Peter Løchte Jørgensen \& Domenico De Giovanni

Time Charters with Purchase Options in Shipping: Valuation and Risk Management

Finance

Research Group 


\title{
Time Charters with Purchase Options in Shipping: Valuation and Risk Management
}

\author{
Peter Løchte Jørgensen* and Domenico De Giovanni ${ }^{\dagger}$ \\ Finance Research Group \\ Department of Business Studies \\ Aarhus School of Business \\ University of Aarhus \\ Fuglesangs Allé 4 \\ DK-8210 Aarhus V \\ DENMARK \\ Phone: + 4589486691 \\ e-mail: plj@asb.dk / dogi@asb.dk
}

Current version: October 6, 2008

JEL Classification Codes: G12 (Asset pricing), G13 (Contingent pricing).

Keywords: Ship valuation, options on ships, leasing, lease contracts with options, optimal stopping.

\footnotetext{
${ }^{*}$ Corresponding author.

†The authors are deeply indebted to Stig Kelstrup and Morten K. Jakobsen of Danish shipping firm D/S Norden for introducing us to shipping derivatives in general and for pointing us to the problem of T/C-POP valuation in particular. Among other things Stig and Morten provided data, literature, crucial market information, examples of actual T/C-POP contracts, and stimulating discussions without all of which this paper could not have been written. We also gratefully acknowledge comments and useful suggestions received from participants at research seminars at the Aarhus School of Business (Nov. 2007), the University of Amsterdam (April 2008), and at the annual meeting of the Danish Center for Accounting and Finance (D-CAF) in May 2008. Any remaining errors are solely the responsibility of the authors.
} 


\title{
Time Charters with Purchase Options in Shipping: Valuation and Risk Management
}

\begin{abstract}
The paper studies the valuation and optimal management of Time Charters with Purchase Options (T/C-POPs) which is a specific type of asset lease with embedded options that is common in shipping markets. T/C-POPs are economically significant and sometimes account for more than half of the stock market value of listed shipping companies.

The main source of risk in markets for maritime transportation is the freight rate, and we therefore specify a single-factor continuous time model for the dynamic evolution of freight rates which allows us to price a wide variety of freight rate related derivatives including various forms of T/C-POPs using contingent claims valuation techniques.

Our model allows for the derivation of closed valuation formulas for some simple freight rate derivatives while the more complex ones are analyzed using numerical (finite difference) procedures. We accompany our theoretical results with illustrative numerical examples as we proceed.
\end{abstract}




\section{Introduction}

Maritime derivatives are increasingly important in international shipping markets. Options, forwards, and futures on freight rate and vessel price indices trade on e.g. the Baltic Exchange, ${ }^{1}$ but options are also embedded in various forms in agreements and contracts between e.g. ship yards and their customers, and between ship owners and ship charterers. An example of this is the Time Charter with Purchase Option - or T/C-POP - which is a common type of contract in shipping markets. From its name it is obvious that the T/C-POP contains one or more options. Not only can the option(s) embedded in T/C-POPs be very complex, but it can also be of significant economic importance. This makes T/C-POPs interesting from both academic and practical business management perspectives.

That T/C-POPs are economically significant is easily verified. We are aware of a number of listed shipping firms which have leased (parts of) their fleets using the T/C-POP type of contract and which in their financial reports explain that more than half of their total reported net asset value stems from an estimated value of their portfolio of T/C-POP contracts. The Danish shipping firm ”D/S Norden” is a concrete example of such a firm. According to their 2007 annual financial report, the total net asset value of the company was DKK614 per share at end-year, and the stock traded more or less at this value. ${ }^{2}$ The report explains that of the DKK614, DKK323 (53\%) stems from a theoretical valuation of the company's 75 T/C-POP contracts. However, the section of D/S Norden's annual financial report which discusses the value of the T/C-POP portfolio concludes that "The calculation of theoretical net asset value is subject to significant uncertainty”. The full details underlying the theoretical valuation methodology are not revealed in the report. Similar results and statements in relation to T/C-POPs can be found in financial reports from other publicly traded shipping firms.

The economic significance of T/C-POPs stresses the need for development and analysis of good valuation models which can support the stock market's valuation of shipping companies, and which can assist managers of such companies in the general process of operation and risk management of their companies. To the authors knowledge there are no previous studies in the academic literature which analyze T/C-POP valuation specifically, and that is therefore the purpose of the present paper. Our methodology will be to implement contingent claims analysis

\footnotetext{
${ }^{1}$ See www.balticexchange.com.

${ }^{2}$ See the website of D/S Norden at www.ds-norden.com.
} 
to the problem of establishing the fair economic value of a number of different variants of T/CPOP contracts. Contingent claims analysis relies on models of the fundamental source(s) of uncertainty, and we argue that in the present context the spot freight rate is the major source of uncertainty. We therefore set up a single-factor model where the (suitably adapted) spot freight rate evolves through time according to a mean reverting stochastic process which has previously been widely applied in financial economics models in general as well as in specific shipping market applications. This particular model has also received some empirical support in relation to freight rate markets, cf. later. In combination with finance theory's standard requirement of absence of arbitrage the model will enable us to study first the valuation of some simple freight rate related derivatives. Next it will enable us to derive valuation expressions and dynamic processes for ship values. These are both essential steps for finally being able to analyze the more composite T/C-POP contracts. As indicated above this paper studies different variants of T/C-POPs. For the European-style T/C-POP we contribute to the library of option pricing formulas with a new closed form valuation formula. But we also study more realistic and complex Bermudan-, American-, and semi-American-style T/C-POPs as well as contracts with options to abandon and/or to extend the time charter. For the more complex contracts, closed form valuation formulas cannot be derived and we therefore devise numerical routines to deal with the valuation of these more complicated structures. A rich variety of numerical examples - some of which are based on true, real-life T/C-POPs - are provided as we proceed. From these examples we learn that additional exotic option features compared with the straight European-style contracts can sometimes add significant value.

The remainder of the paper is organized as follows. Section 2 introduces T/C-POPs and explains their typical structure in more detail. Section 3 sets up the single-factor model of freight rate uncertainty which forms the basis for valuing freight rate contingent claims ranging from the simplest ones (section 4) to the most exotic forms of T/C-POPs (section 5). Section 6 contains our final remarks and concludes. 


\section{Time Charters with Purchase Options}

A time charter (T/C) contract in the shipping market is an agreement between a ship owner and a ship operator (charterer) in which the ship operator agrees to pay a fixed (typically daily USD) charter rate to the ship owner for a fixed period of time. In return for the charter rate paid the ship operator acquires the right to operate the ship as he likes during the charter period. This will enable the charterer to capture the spot freight rate in the market for maritime transportation for the duration of the charter period. The spot (daily) freight rate varies in a stochastic manner through time and is the main source of business risk in shipping.

Time charters are often long term contracts ranging in length from a few weeks or months and up to 15 years or more. Moreover, the right to operate the ship often includes some kind of option to purchase the ship (and thus canceling the charter contract) for a given price on one or more specified future points in time. Hence the name Time Charters with Purchase Options or simply T/C-POPs.

In practice various forms of purchase (or call) options are seen. A European-style T/C-POP is a time charter contract where the charterer can purchase the ship for a given price at the expiration date of the charter contract. The value of such a contract can be established in explicit form in the model that we develop below. In the pure American-style T/C-POP the charterer can exercise his right to purchase the ship and stop paying the charter rate at any time until the charter contract expires. Some T/C-POPs are American-style but with an initial lock-up period such that there is a right to purchase the ship anytime after a certain number of years in charter. The purchase option may also be of Bermudan style with a finite and distinct number of exercise dates. When there are more than one exercise point the strike price of the option will typically vary as a deterministic (and decreasing) function of time.

The valuation of American- or Bermudan-style T/C-POPs is significantly more involved than the valuation of their European counterparts. The question of optimal timing of the exercise decision for these options further complicates matters. This issue will be dealt with in more detail below.

To the authors' knowledge this paper is the first which considers the valuation and optimal management of the common T/C-POP contract in shipping markets. However, since T/C-POPs is a very specific form of lease contract with an option to purchase the underlying (real) asset we can indeed point the interested reader to previous literature which treats the subject of lease contracts 
with options from a more general perspective. For example, McConnell and Schallheim (1983) set up a discrete time model in which they consider the general valuation of a variety of different types of asset leasing contracts. Examples of such contracts are 1) leases that grant the lessee an option to purchase the leased asset at a fixed price at the maturity date of the lease, 2) leases that grant an option to the lessee to purchase the leased asset at a prespecified price anytime during the life of the lease, and, 3) leases which grant the lessee an option to extend the life of the lease. Another key reference in this respect is Trigeorgis (1996) which deals with the numerical valuation of leasing contracts with a variety of complex embedded operating options including purchase options, exit options, and options to extend.

\section{A One-factor Model of Freight Rate Uncertainty}

As explained above, T/C-POPs contain an option to buy a ship. Such call options are valuable and their values vary through time because ship prices are uncertain. Market values of ships vary mainly because freight rates are volatile. The high correlation between freight rates and ship prices is well documented in the literature, see for example Adland and Koekebakker (2007) and Kavussanos and Visvikis (2006) and references therein.

In order to value T/C-POPs we will first introduce a model for the stochastic dynamics of the spot freight rate. Assuming further that the spot freight rate is the single factor driving returns in the shipping markets, our model will enable us not only to derive formulas for the value of simple freight rate related instruments but also to characterize ship values and their dynamics through time. This will in turn enable us to analyze the valuation of options with ships as underlying assets.

\subsection{Modeling freight rate dynamics}

Empirical research into freight rate dynamics has found strong evidence of mean reversion in freight rate markets (see e.g. Adland (2000) and Alesii (2005)). For this and a number of other reasons that will be explained below we have chosen to adopt the freight rate model of Bjerksund and Ekern (1995) for our analysis of shipping derivatives and especially T/C-POPs.

The basic assumptions in the Bjerksund-Ekern model are as follows. The instantaneous cash 
flow from an operating ship is given as

$$
D(t) d t=(a X(t)-b) d t
$$

where $X(t)$ is the (annualized) spot freight rate at time $t$ per unit of cargo, $a$ is the cargo size, and $b$ is the total cost flow rate. ${ }^{3}$ In this paper we will assume for ease of notation that the freight rate is quoted for the entire ship and net of all costs such that $a=1$ and $b=0$. Our $X(t) d t$ is thus the instantaneous net profits from an operating ship. This is important to note when making comparisons with market quoted freight rates which embed a varying degree of costs. Although transformations of market quoted freight rates may thus be needed for correct comparisons we will nonetheless refer to $X(t)$ as the spot freight rate in the following.

Bjerksund and Ekern (1995) propose to model the spot freight rate as a mean reverting Ornstein-Uhlenbeck-process. This is identical to the famous process for interest rate dynamics proposed in Vasicek (1977). In relation to freight rate modeling this process has been applied and/or received empirical support in e.g. Adland (2000), Adland and Cullinane (2006), Alesii (2005), and Tvedt (1997). The dynamics of the spot freight rate is thus modeled by the following stochastic differential equation,

$$
d X(t)=\kappa(\theta-X(t)) d t+\sigma d \mathcal{W}(t)
$$

where $\theta$ is the constant long term mean, $\kappa$ is the speed of mean reversion, $\sigma$ is the instantaneous volatility of spot freight rates, and $\mathcal{W}(\cdot)$ is a standard Wiener process defined on some probability space $(\Omega, \mathcal{F}, P)$. Note that time is measured in years and that since actual freight rates are normally quoted on a daily basis we need to consider $X(t) \Delta t$ - where $\Delta t$ is one day measured in years, ie. about 1/360 year - for comparisons with market data. The continuously compounded riskless interest rate, $r$, is assumed to be constant.

The model above implies that future spot freight rates are normal distributed. More precisely, since the stochastic differential equation in (2) implies the explicit solution

$$
X(T)=X(t) e^{-\kappa(T-t)}+\theta\left(1-e^{-\kappa(T-t)}\right)+\sigma \int_{t}^{T} e^{-\kappa(T-u)} d \mathcal{W}(u)
$$

we can state the time $t$ conditional mean and variance of the normal distributed future rate $X(T)$

\footnotetext{
${ }^{3}$ The spot freight rate concept that we operate with here is comparable to what is sometimes called the voyage charter rate, cf. Kavussanos and Visvikis (2006). See e.g. their footnote on p. 32 and plots on p. 44 and 45.
} 
as follows,

$$
\begin{aligned}
E_{t}\{X(T)\} & =X(t) e^{-\kappa(T-t)}+\theta\left(1-e^{-\kappa(T-t)}\right) \\
\operatorname{Var}_{t}\{X(T)\} & =\sigma^{2} \int_{t}^{T} e^{-2 \kappa(T-u)} d u=\frac{\sigma^{2}}{2 \kappa}\left(1-e^{-2 \kappa(T-t)}\right) .
\end{aligned}
$$

For more on stochastic differential equations and their solutions the reader is referred to Arnold (1992).

\subsection{Valuation of freight rate contingent claims}

In the following we will focus on those claims or instruments with values, $V(X, t)$, which are influenced only by the freight rate factor process, $X(t)$, and time. Using Ito's lemma and standard no arbitrage arguments (see e.g. Duffie (2001) or Hull (2006)) it can be seen that such claims must satisfy the following partial differential equation

$$
\kappa\left(\theta-\frac{\sigma \lambda(X, t)}{\kappa}-X(t)\right) \frac{\partial V(X, t)}{\partial X}+\frac{1}{2} \sigma^{2} \frac{\partial^{2} V(X, t)}{\partial X^{2}}+\frac{\partial V(x, t)}{\partial t}-r V(x, t)+\Gamma(X, t)=0 .
$$

In the equation above $\lambda(X, t)$ is the market price of freight rate risk and $\Gamma(X, t) d t$ is the instantaneous net dividend received by the claim $V$ at time $t$. We will henceforth assume that the market price of freight rate risk is constant and define $\theta^{*} \equiv \theta-\frac{\sigma \lambda}{\kappa}$ so that (6) can be rewritten (with obvious shorthand notation) as

$$
\kappa\left(\theta^{*}-X(t)\right) V_{x}+\frac{1}{2} \sigma^{2} V_{x x}+V_{t}-r V+\Gamma(X, t)=0 .
$$

For a particular claim (defined precisely by its boundary conditions) one can attempt to solve (7) directly or numerically subject to the relevant boundary and terminal conditions. Another possibility would be to manipulate the probabilistic Feynman-Kac representation of the solution to (7) (see e.g. Duffie (2001)). This takes the form

$$
V(X, t)=E_{t}^{Q}\left\{\int_{t}^{T} \Gamma\left(X_{u}, u\right) e^{-r(u-t)} d u+e^{-r(T-t)} V\left(X_{T}, T\right)\right\},
$$

where $T$ would typically be the expiration date at which time the claim value would be given as a known function of $X(T)$. Expression (8) is quite intuitive in that the present value is expressed as an expectation of the discounted value of the continuous flow of net dividends plus the discounted value of the payoff at the maturity date. The riskless interest rate is used for discounting since the adjustment for risk is in the probabilities. The conditional expectation in 
(8) is thus formed with respect to the risk neutral probability measure, $Q$, under which $X(t)$ has dynamics

$$
d X(t)=\kappa\left(\theta^{*}-X(t)\right) d t+\sigma d \mathcal{W}^{Q}(t)
$$

and where according to Girsanov's theorem (see Duffie (2001))

$$
d \mathcal{W}^{Q}(t)=d \mathcal{W}(t)+\lambda d t
$$

The explicit solution of (9) is of course given as in (3), but with $\theta$ replaced by $\theta^{*}$. The same holds for the conditional mean (see (4)), whereas the conditional variance (see (5)) remains unchanged under the $Q$-measure.

We have now progressed far enough to start valuing some basic freight rate related claims. 


\section{Valuing Some Simple Freight Rate Dependent Claims}

This section presents valuation formulas for a variety of simple freight rate contingent claims. The analysis will serve to illustrate the earlier presented general valuation principles and it will lay the foundation for our later treatment of the more complex time charters with purchase options.

\subsection{Claim to receive spot freight rate flow from time $t$ to time $T$}

Let $V^{\text {Flow }}(X(t), t ; T)$ denote the time $t$ value of a claim to receive the spot freight rate on a continuous basis from time $t$ (when the current freight rate is $X(t)$ ) and until time $T, T>t$. Using (8) we easily derive a closed form expression for this value. We get

$$
\begin{aligned}
V^{\text {Flow }}(X(t), t ; T) & =E_{t}^{Q}\left\{\int_{t}^{T} e^{-r(u-t)} X(u) d u\right\} \\
& =\left(X(t)-\theta^{*}\right) A(T-t, r+\kappa)+\theta^{*} A(T-t, r),
\end{aligned}
$$

where $A(\tau, \delta) \equiv \frac{1-e^{-\delta \tau}}{\delta}$ is an annuity factor, ie. the present value using discount rate $\delta$ of receiving a unitized continuous cash flow for $\tau$ years. We may note that $V^{\text {Flow }}(\cdot)$ is linear in $X(t)$ and thus normal distributed as seen from any time point prior to $t$.

\subsection{Fixed for floating freight rate swap}

In connection with the analysis of the spot contract above it may be relevant to determine the constant freight rate, $\bar{X}_{t, T}$, fixed at time $t$ that will be equivalent to receiving the variable spot freight rate over the period from time $t$ to time $T$. This is completely parallel to fixing the swap rate in plain vanilla interest rate swaps. To solve this problem we use (11) and solve

$$
\bar{X}_{t, T} A(T-t, r)=\left(X(t)-\theta^{*}\right) A(T-t, r+\kappa)+\theta^{*} A(T-t, r)
$$

for the unknown fixed time charter (T/C) rate. We get

$$
\bar{X}_{t, T}=\theta^{*}+\frac{A(T-t, r+\kappa)}{A(T-t, r)}\left(X(t)-\theta^{*}\right) .
$$

To reiterate, $\bar{X}_{t, T}$ will be the fair continuously paid constant T/C rate which should make the shipowner indifferent (from a valuation perspective) between receiving the spot freight rate and the fixed T/C rate during the life of the contract. Note that although the present values of the 
alternatives are equal, the risks inherent in the two contract types clearly differ. As an example of the use of (13), consider a 5 year time charter contract and suppose that $r=5 \%$ and that $\theta^{*}=20000$ (on a daily basis). The table below indicates the fair daily time charter rate as a function of the current spot freight rate and the mean reversion rate $(\kappa)$. Here and in the remainder of the paper we assume that 1 year equals 360 days.

\section{Table 1:}

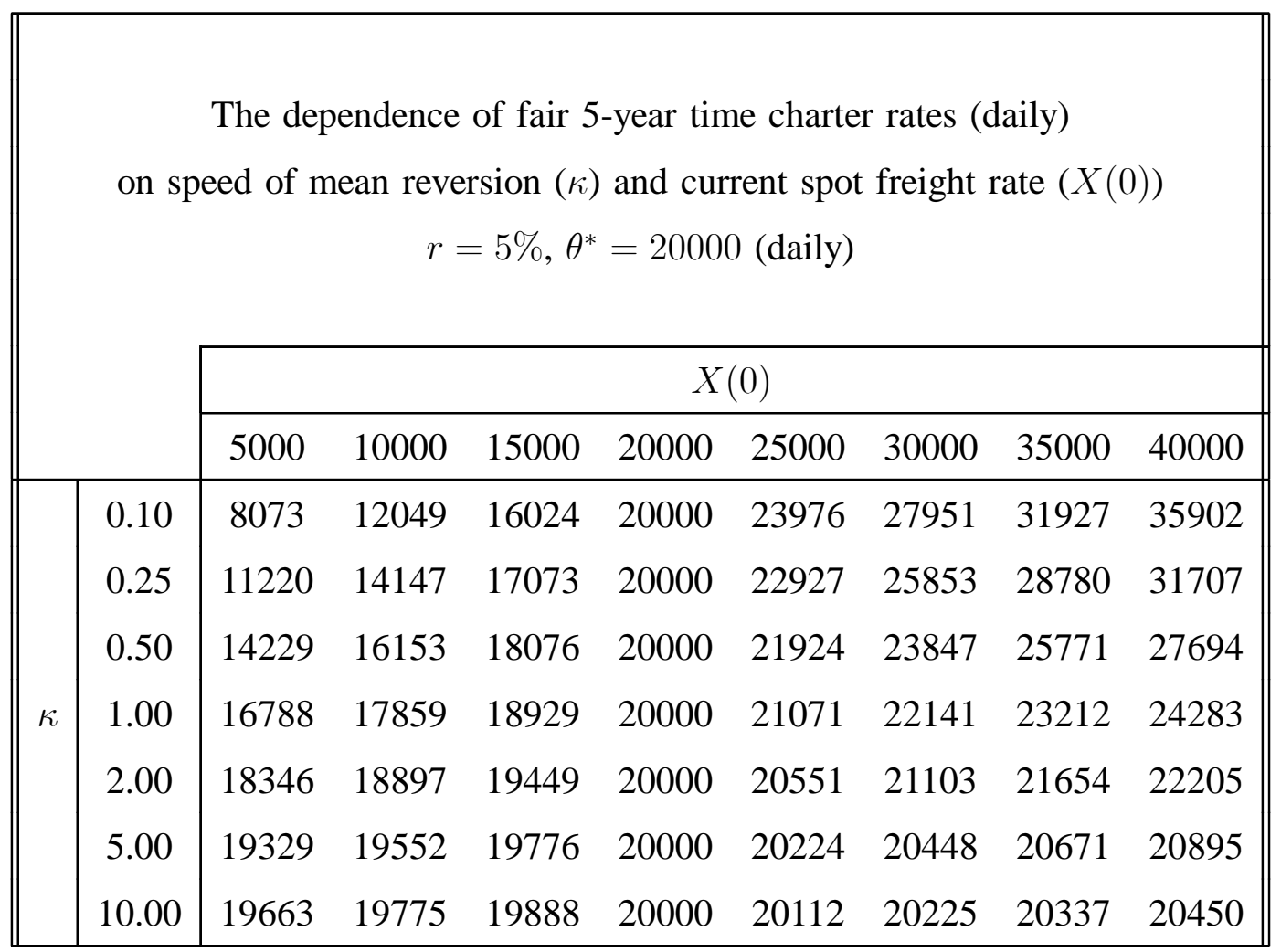

A brief look at table 1 confirms that fair T/C rates react in accordance with intuition: When the current spot rate and the long term mean coincide - in this example at 20000 per day - then the fair T/C rate takes the same value regardless of the rate of mean reversion. However, the mean reversion rate is important when current spot rates differ from their long run mean. Fair T/C rates are closer to current spot rates the weaker the mean reversion. On the contrary, when mean reversion is very strong, then the current spot rate has little effect and fair T/C rates are closer to the long run mean as spot rates are also expected to quickly revert to this level.

Similarly to fixing current fair T/C rates we could value a time charter contract at time $t$ that has previously (at time $s<t$ ) been entered into at fixed rate $\bar{X}_{s, T}$. For a contract that receives 
the floating spot rate and pays a fixed $\mathrm{T} / \mathrm{C}$ rate we find

$$
V^{S w a p}(t ; s, T)=\left[\bar{X}_{t, T}-\bar{X}_{s, T}\right] A(T-t, r) .
$$

This is a quite intuitive result. We see that if the contracted time charter rate is higher than the prevailing fair rate, then the swap has a negative value and vice versa. The value equals the discounted value of the continuous flow of the spread difference.

As an example of the use of (14) let us consider a time charter contract with 5 years to maturity and suppose that $r=5 \%$. In addition let $\theta^{*}=20000$ per day, and let $\kappa=0.25$. The table below indicates the value of this "swap" as a function of the (previously) contracted time charter rate and the current spot freight rate / fair charter rate.

\section{Table 2:}

The value of a 5-year time charter contract (in millions) Dependence on current and previously contracted daily $\mathrm{T} / \mathrm{C}$ rates

$$
r=5 \%, \theta^{*}=20000 \text { per day, } \kappa=0.25
$$

\begin{tabular}{||c|c|cccc||}
\hline \multicolumn{2}{||c|}{ Spot and current T/C rate } & \multicolumn{4}{|c||}{$\bar{X}_{s, T}$, previously contracted rate } \\
\hline$X(t)$ & $\bar{X}_{t, T}$ & 5000 & 10000 & 20000 & 30000 \\
\hline 5000 & 11220 & 9.906 & 1.943 & -13.984 & -29.910 \\
10000 & 14147 & 14.567 & 6.604 & -9.322 & -25.249 \\
20000 & 20000 & 23.890 & 15.926 & 0.000 & -15.926 \\
30000 & 25853 & 33.212 & 25.249 & 9.322 & -6.604 \\
\hline
\end{tabular}

Again the general effects are as expected. The higher the previously contracted rate (which must be PAID) is in comparison with current spot rates (or current fair T/C rates), the lower the contract value, and vice versa.

\subsection{The value of a ship}

A ship is a physical asset that earns rents to its owner in the form of the flow of the (net) spot freight rates for the duration of the ship's limited life. It is typically assumed that a new ship 
has a life of 25-30 years (Adland and Koekebakker (2007)). When a ship reaches the end of its useful economic life it will have a scrap value, mainly because of the value of the significant amount of recyclable steel used to build the hull. Assuming that the final service date, $\bar{T}$, of a ship as well as its scrap value, $\bar{V}$, are known with certainty, we can value the ship at date $t$ as a small extension of expression (11) above:

$$
V^{\text {ship }}(X(t), t ; \bar{T})=\left(X(t)-\theta^{*}\right) A(\bar{T}-t, r+\kappa)+\theta^{*} A(\bar{T}-t, r)+e^{-r(\bar{T}-t)} \bar{V} .
$$

In the table below we have calculated some ship values for representative parameter values using relation (15).

\section{Table 3:}

\begin{tabular}{|c|c|c|c|c|c|c|}
\hline \multicolumn{7}{|c|}{$\begin{array}{l}\text { The dependence of ship values (in millions) } \\
\text { on remaining ship life }(\bar{T}-t) \text { and the spot freight rate }(X(t)) \\
\qquad \kappa=0.25, \theta^{*}=20000 \text { per day, } r=5 \%, \bar{V}=5 \mathrm{~m}\end{array}$} \\
\hline & & \multicolumn{5}{|c|}{ Remaining ship life $(\bar{T}-t)$} \\
\hline & & 5 & 10 & 15 & 20 & 25 \\
\hline \multirow{8}{*}{$X(t)$} & 5000 & 21.763 & 42.588 & 60.541 & 74.909 & 86.186 \\
\hline & 10000 & 26.424 & 48.290 & 66.474 & 80.895 & 92.182 \\
\hline & 15000 & 31.085 & 53.991 & 72.408 & 86.880 & 98.179 \\
\hline & 20000 & 35.747 & 59.692 & 78.341 & 92.865 & 104.176 \\
\hline & 25000 & 40.408 & 65.394 & 84.274 & 98.850 & 110.173 \\
\hline & 30000 & 45.069 & 71.095 & 90.208 & 104.835 & 116.169 \\
\hline & 35000 & 49.730 & 76.796 & 96.141 & 110.820 & 122.166 \\
\hline & 40000 & 54.392 & 82.497 & 102.074 & 116.805 & 128.163 \\
\hline
\end{tabular}

From table 3 we observe that ship values can be very sensitive to spot freight rates when mean reversion is fairly weak. Also as expected, ship values decrease significantly as the ship ages.

It may be noted from (15) that $V^{\text {ship }}(\cdot)$ follows a Gaussian process with deterministically time-varying drift and diffusion coefficients. Future ship values at any time $T<\bar{T}$ are in other 
words normal distributed under both the $P$ and $Q$ probability measures with conditional means and variance (under the various probability measures) as given below:

$$
\begin{aligned}
E_{t}^{Q}\left\{V^{\text {ship }}(X(T), T ; \bar{T})\right\}= & e^{-\kappa(T-t)}\left(X(t)-\theta^{*}\right) A(\bar{T}-T, r+\kappa) \\
& +\theta^{*} A(\bar{T}-T, r)+e^{-r(\bar{T}-T)} \bar{V}, \\
E_{t}\left\{V^{\text {ship }}(X(T), T ; \bar{T})\right\}= & \left(e^{-\kappa(T-t)}(X(t)-\theta)+\left(\theta-\theta^{*}\right)\right) A(\bar{T}-T, r+\kappa) \\
& +\theta^{*} A(\bar{T}-T, r)+e^{-r(\bar{T}-T)} \bar{V}, \\
\operatorname{Var}_{t}^{(Q)}\left\{V^{\text {ship }}(X(T), T ; \bar{T})\right\}= & A^{2}(\bar{T}-T, r+\kappa) \frac{\sigma^{2}}{2 \kappa}\left(1-e^{-2 \kappa(T-t)}\right) .
\end{aligned}
$$

In Figure 1 below we have plotted a simulated scenario of the ship value dynamics along with its $Q$-mean and a 95\% probability "confidence” band using expressions (15)-(18) . It can be seen that the ship value is expected to decrease from its current value to its scrap value, and that uncertainty (the width of the confidence band) first increases and then decreases again as the scrap date nears.

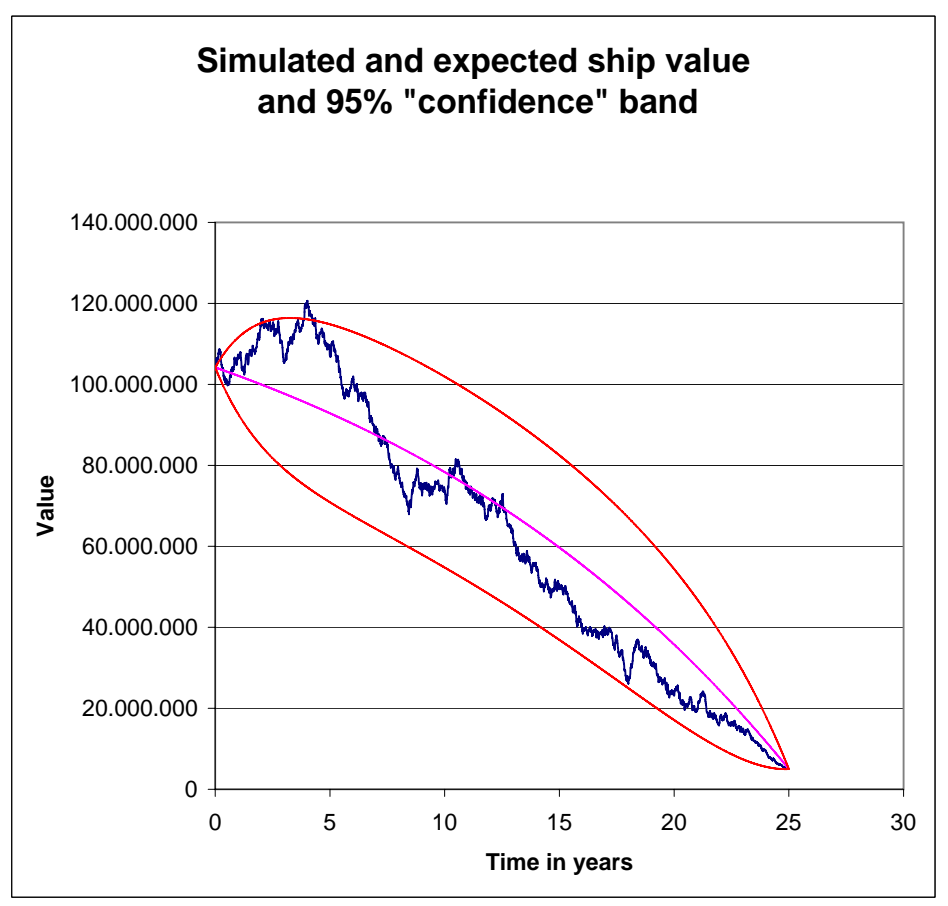

Figure 1: Simulated evolution in ship value along with expectation and 95\% probability band. $\kappa=0.25, r=0.05, \bar{T}=25, \bar{V}=5 \mathrm{~m}, \theta^{*}=20000, \sigma=5000$. 


\subsection{European option to buy ship}

With the ship value process and future ship price distribution well established we can now present this article's first option valuation result.

Let the current date be $t$ and let $T$ denote the expiration date of a European option to buy a ship which must be scrapped at date $\bar{T}$ for a value of $\bar{V}$. If we let $K$ denote the exercise price of the call option then the payoff function, $c(X(T), T)$, is given as

$$
c(X(T), T)=\max \left(V^{s h i p}(X(T), T ; \bar{V})-K ; 0\right) .
$$

In the appendix we show that the time $t$ value of this European call option is given as

$$
c(X(t), t)=e^{-r(T-t)} A(\bar{T}-T, r+\kappa) v_{t, T}(\xi N(\xi)+n(\xi)),
$$

where

$$
\begin{aligned}
\xi & =\frac{m_{t, T}-\overline{\bar{K}}}{v_{t, T}}, \\
m_{t, T} & =E_{t}^{Q}\{X(T)\}=X(t) e^{-\kappa(T-t)}+\theta^{*}\left(1-e^{-\kappa(T-t)}\right), \\
\overline{\bar{K}} & =\frac{K+\theta^{*}(A(\bar{T}-T, r+\kappa)-A(\bar{T}-T, r))-e^{-r(\bar{T}-T)} \bar{V}}{A(\bar{T}-T, r+\kappa)}, \\
v_{t, T}^{2} & =\operatorname{Var}_{t}^{(Q)}\{X(T)\}=\frac{\sigma^{2}}{2 \kappa}\left(1-e^{-2 \kappa(T-t)}\right),
\end{aligned}
$$

and where $N(\cdot)$ and $n(\cdot)$ denote the standard normal cumulative probability and density functions respectively.

We note that a valuation formula for European options on a normal distributed underlying asset value in a constant (or deterministic) interest rate environment is by no means a new result. It dates back at least to the seminal work by Bachelier (1900). For more recent derivations the reader is referred to Goldenberg (1991) and to Bjerksund and Ekern (1995) which has an almost identical result to ours although the authors do not interpret the underlying contract as a "ship". 
Table 4:

\begin{tabular}{|c|c|c|c|c|c|c|}
\hline \multicolumn{7}{|c|}{$\begin{array}{l}\text { Value of European option to buy ship (in millions) } \\
\text { Dependence on spot freight rate and freight rate volatility } \\
\qquad \begin{array}{l}r=5 \%, \kappa=0.25, \theta^{*}=20000 \text { per day, } \bar{V}=5 \mathrm{~m} \\
\qquad t=0, T=5, \bar{T}=25, K=93 \mathrm{~m}\end{array}\end{array}$} \\
\hline & & \multicolumn{5}{|c|}{ Freight rate volatility, $\sigma$ (daily) } \\
\hline & & 1000 & 3000 & 5000 & 7000 & 9000 \\
\hline \multirow{6}{*}{$\begin{array}{l}\text { Spot freight rate } \\
\qquad X(0)\end{array}$} & 5000 & 0.000 & 0.268 & 0.980 & 1.846 & 2.773 \\
\hline & 10000 & 0.006 & 0.512 & 1.371 & 2.312 & 3.282 \\
\hline & 15000 & 0.080 & 0.899 & 1.864 & 2.854 & 3.851 \\
\hline & 20000 & 0.453 & 1.460 & 2.467 & 3.475 & 4.483 \\
\hline & 25000 & 1.341 & 2.206 & 3.182 & 4.177 & 5.177 \\
\hline & 30000 & 2.575 & 3.128 & 4.007 & 4.958 & 5.933 \\
\hline
\end{tabular}

Table 4 shows some representative ship option values according to formula (20) for varying spot freight rates and freight rate volatilities. The strike price has been set approximately equal to the expected ship value at the option's maturity date (the forward ship price), cf. expression (16). As expected option values are seen to increase as both spot freight rates and freight rate volatility increase.

\subsection{Time charter with European purchase option}

We are steadily approaching the goal of being able to value and analyze time charter contracts with purchase options, and with the option pricing result from above we are now in a position to exemplify the valuation of the simplest conceivable T/C-POPs, namely time charter contracts with a European-type option to buy the underlying ship at the expiration date of the lease period. Since the option is European in this case we can safely decompose the contract into its leasing contract component and its option contract component and perform the valuation of these two elements separately. The total T/C-POP value will thus be the sum of the value of the floatingfor-fixed freight rate swap contract (see (14)) and the value of the European option as given in 
(20). As we have seen, both contract values are positively related to the spot freight rate, but whereas the option value is bounded below by zero, the swap contract value will be negative for sufficiently low spot freight rates. This means that the total value of the time charter with European purchase option can become negative. In table 5 below we show total values as a function of the fixed lease rate and the current spot freight rate.

\section{Table 5:}

\begin{tabular}{|c|c|c|c|c|c|c|c|}
\hline \multicolumn{8}{|c|}{$\begin{array}{l}\text { The value of a time charter contract with European purchase option (in millions) } \\
\text { Dependence on contracted charter rate and current spot freight rate } \\
\qquad \begin{array}{c}r=5 \%, \kappa=0.25, \theta^{*}=20000 \text { per day, } \sigma=5,000 \text { per day } \\
\qquad \bar{V}=5 m, t=0, T=5, \bar{T}=25, K=93 \mathrm{~m}\end{array}\end{array}$} \\
\hline & & \multicolumn{6}{|c|}{ Fixed T/C rate (daily) } \\
\hline & & 5000 & 10000 & 15000 & 20000 & 25000 & 30000 \\
\hline \multirow{6}{*}{$\begin{array}{c}\text { Spot freight rate } \\
\qquad X(0)\end{array}$} & 5000 & 10.885 & 2.922 & -5.041 & -13.004 & -20.967 & -28.930 \\
\hline & 10000 & 15.938 & 7.975 & 0.012 & -7.951 & -15.915 & -23.878 \\
\hline & 15000 & 21.093 & 13.130 & 5.166 & -2.797 & -10.760 & -18.723 \\
\hline & 20000 & 26.357 & 18.394 & 10.430 & 2.467 & -5.496 & -13.459 \\
\hline & 25000 & 31.733 & 23.770 & 15.807 & 7.843 & -0.120 & -8.083 \\
\hline & 30000 & 37.219 & 29.256 & 21.293 & 13.330 & 5.367 & -2.596 \\
\hline
\end{tabular}




\section{Valuing More Complex T/C-POPs}

In the previous section we focused on relatively simple types of freight rate derivatives and closed-form pricing expressions were established in all of the cases. However, the actual T/CPOP contracts that have inspired the present paper and which appear to be typical in the shipping business are more complex than was assumed in the previous section. Real-life T/C-POP contracts will typically entail some kind of American or semi-American exercise feature. ${ }^{4}$ Moreover, the exercise prices of the options will typically vary in some deterministic fashion through time reflecting to some extent the expected decrease in ship values over time, cf. also section 4. Early exercise features in particular will make option valuation more involved and almost always impede the derivation of closed-form valuation formulas. It will also raise the additional question of how the option to exercise prematurely should be managed to maximize its value. This section will therefore introduce and analyze a number of more complex T/C-POP contracts. During the course of the analysis we adapt and illustrate a finite difference based numerical algorithm that can be implemented for both valuation and for establishing optimal strategies in relation to these contracts.

We first consider the "pure” American-style T/C-POP at a quite abstract level, and we then move on to consider two case studies that are based on actual T/C-POP contracts from practice. The first of these is a 15-year Bermudan type T/C-POP on a Capesize vessel negotiated in February 2007 between the NYSE listed Ship Finance International Ltd. and OSE listed Norwegian shipping firm Golden Ocean Group Ltd. Our second case study is a semi-American 5-year (but extendable) T/C-POP involving a Panamax sized vessel. This contract was negotiated between the Danish shipping firm D/S Norden (listed on the Copenhagen Stock Exchange) and a Japanese shipyard in March of 2004. It is semi-American because there is an initial 3-year lockup period where the purchase option cannot be exercised and also a string of three consecutive 1-year options to extend the lease in the final three years of the contract.

\subsection{Numerical considerations and the pure American-style T/C-POP}

When pricing T/C-POPs with early exercise features the valuation problem involves the identification of an optimal stopping time. In order to fix some general ideas we consider in this

\footnotetext{
${ }^{4}$ The semi-American exercise feature could for example be Bermudan (exercise allowed on a finite number of distinct points in time before maturity), or it could be standard American after a certain lock-up period.
} 
section the valuation of a pure American-style T/C-POP and we present the basics of a numerical procedure that can be implemented to solve this problem. The pure American T/C-POP contract is similar to the European T/C-POP which was considered above except that the underlying ship can be purchased at the prespecified (possibly time varying) strike price $K(\cdot)$ at any time on or before the maturity date $T$. This is illustrated in the time line in Figure 2 below.
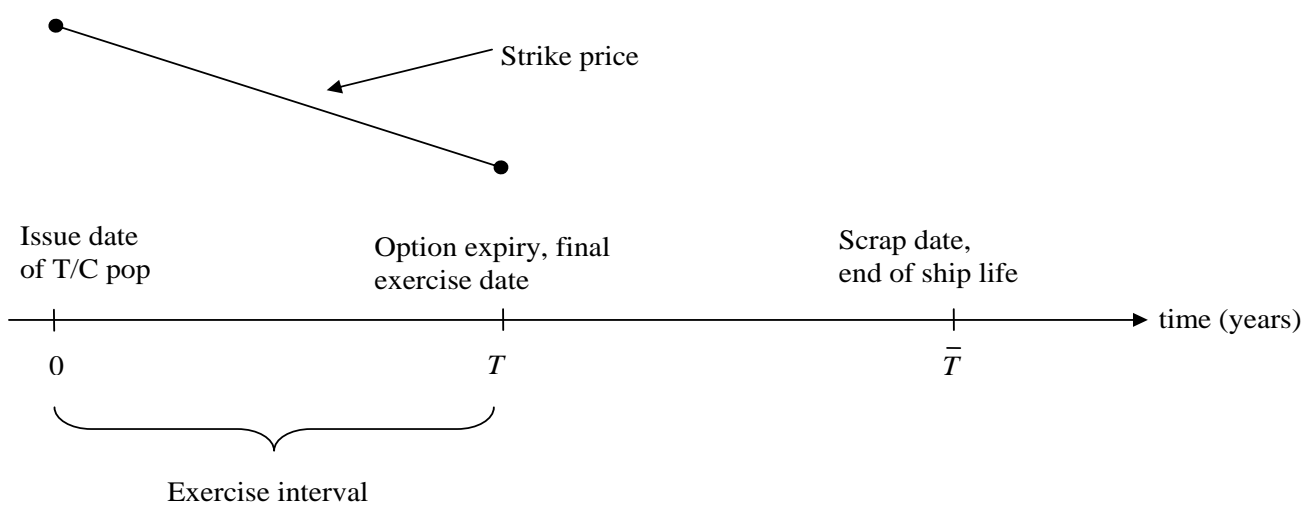

Figure 2: Structure of the pure American T/C-POP contract.

If the option to buy the ship is exercised, the lease payments, $\bar{X}(\cdot)$, are immediately terminated. The optimal exercise decision therefore involves a careful balancing act where current and (expected) future spot rates, lease rates, ship values, and exercise prices are weighed against each other. As seen from time 0 the optimal stopping time is a stochastic variable. If we denote it by $\tau$, we can express the value of the pure American-style T/C-POP at time 0 as

$$
\begin{aligned}
C\left(X_{0}, 0\right)=\sup _{\tau \in \mathcal{S}_{[0, T]}} & E_{0}^{Q}\left\{\int_{0}^{\tau} e^{-r u}(X(u)-\bar{X}(u)) d u\right. \\
& +e^{-r \tau}\left(V^{\operatorname{ship}}(X(\tau), \tau)-K(\tau)\right) \cdot 1_{\{\tau<T\}} \\
& \left.+e^{-r T}\left(V^{\operatorname{ship}}(X(T), T)-K(T)\right)^{+} \cdot 1_{\{\tau \geq T\}}\right\}
\end{aligned}
$$

where $\mathcal{S}_{[0, T]}$ denotes the set of all admissible stopping rules taking values in $[0, T]$ (see e.g. Duffie (2001)). The first term inside the risk neutral expectations operator in (21) is the discounted value of the flow of net profits of the lease until the purchase option is exercised or expires, whichever comes first. The second term represents the discounted value of the payoff from the purchase option if exercised prematurely. Finally, the third term represents the discounted value of the previously unexercised contract precisely at the maturity date. It is necessary to separate the 
second and third terms in this way since it is conceivable (see also the following example) that an out of the money purchase option will be exercised prematurely (since a very unfavorable lease can be terminated in this way). The payoff function at maturity (third term) is more standard.

Unfortunately expressions such as relation (21) are not operational in practice and very few optimal stopping problems allow for the derivation of closed form solutions. So even for this slightly extended T/C-POP contract we will have to rely on some numerical solution routine for solving the problem. One such very suitable numerical method is a finite difference based solution of the fundamental partial differential equation with its appropriate boundary conditions. We have implemented such an algorithm to illustrate solutions both in the present case of the pure American-style T/C-POP, and in the subsequent more complex case studies. The point of departure of this algorithm - the details of which have been relegated to the appendix - is the PDE in (6). When applied to the pure American contract the main steps of this algorithm are as follows:

1. We first impose an equidistant grid on a truncated state space of the contract, ie. on $[0, T] \times\left[X_{\min }, X_{\max }\right]$, where $X_{\min }$ and $X_{\max }$ are carefully chosen lower and upper cut-off points for the $X$-state-variable - the freight rate (see Figure 3). We can let the analytically calculable probabilities of exceeding these bounds - given the initial condition and other process parameters - guide our choice of $X_{\min }$ and $X_{\max } .^{5}$ The step lengths $\Delta t$ and $\Delta X$ are chosen such that $I \equiv \frac{T}{\Delta t}$ and $J \equiv \frac{\left(X_{\max }-X_{\min }\right)}{\Delta X}$ are positive integers. $I$ and $J$ are thus the number of steps in the time and freight rate dimensions respectively. The contract value in grid point $(i, j)$ is $C^{i, j}=C\left(X_{\min }+j \cdot \Delta X, i \cdot \Delta t\right)$.

2. Valuation is initiated at the back end of the grid where contract values are given in closed form thanks to our analytic expression of ship values, see (15). We simply set

$$
C^{I, j}=\left[V^{\text {ship }}\left(X_{\min }+j \cdot \Delta X, T\right)-K(T)\right]^{+}, \quad \forall j \in[0, J] .
$$

3. Next, $i$ is decreased by one and we move one time step "backwards", ie. one step closer to the initial time. In each of the nodes at this time we can calculate the value of stopping immediately in closed form. This value should be compared to the alternative of continuing. The continuation value is established by the finite difference algorithm which in an appropriate manner (see the appendix) weighs and discounts the contract values from the previous

\footnotetext{
${ }^{5}$ It could seem natural to let $X_{\min }=0$, but since the process (3) allows for negative $X$-values, more care is needed in setting $X_{\min }$.
} 
step and also takes cash flows during the subsequent $\Delta t$-interval (freight rate received and lease rate paid) into account. The optimal exercise strategy is the state-contingent exercise strategy that maximizes the contract value.

4. Step 3 is repeated until $i=0$. This means that contract values are determined in all states (ie. $\forall j \in[0, J]$ ) at time 0 , and we are done.

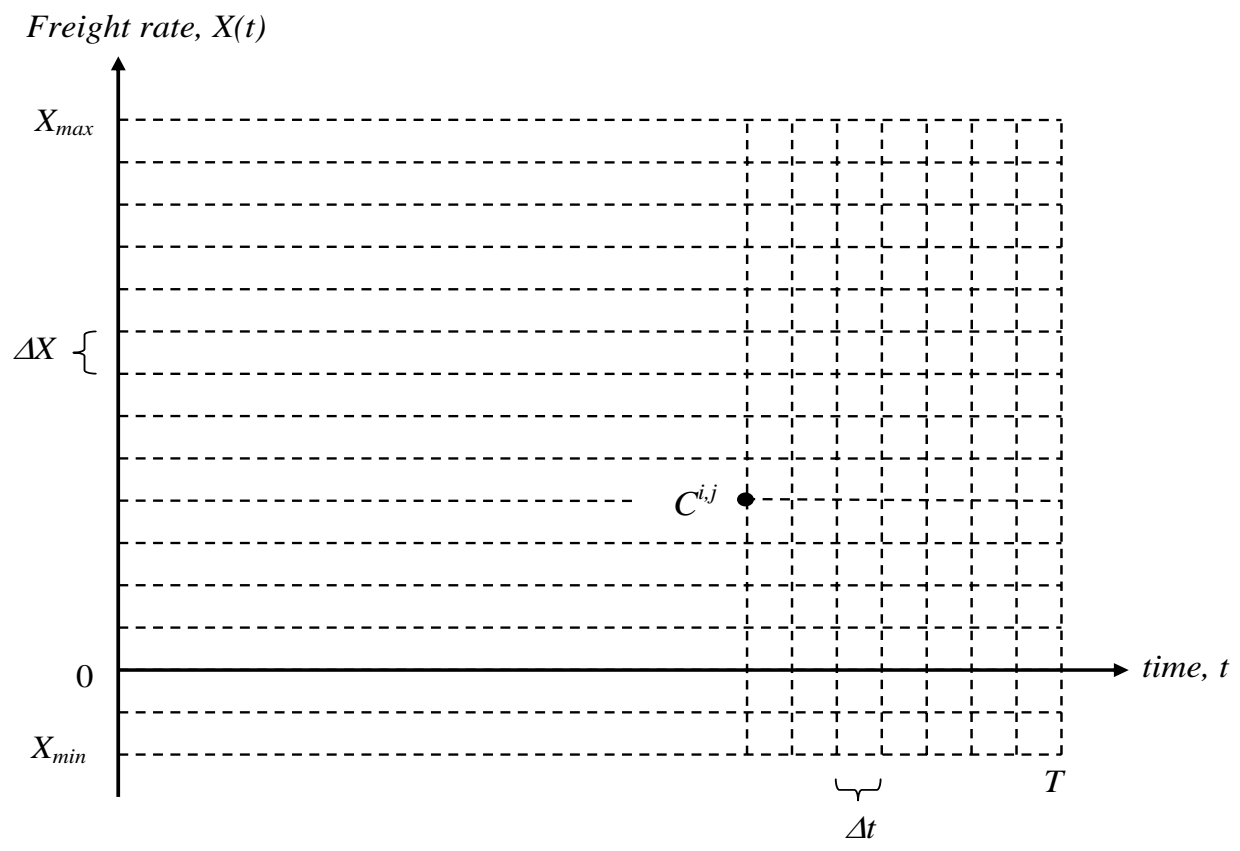

Figure 3: Finite difference scheme grid structure.

We can now present some numerical results from the implementation of this finite difference algorithm for solving the pure American-style T/C-POP valuation problem. Our base case parameters will be as before (see tables 1-5), but we must now specify a full strike price function, $K(t)$, for $t \in[0 ; 5]$ as opposed to the single fixed strike price for the European contract. For both figure 4 and table 6 below we have used a linearly decreasing strike function starting from $K(0)=102 \mathrm{~m}$ and ending at $K(5)=92.865 \mathrm{~m}$ at the option's maturity date. For the base case choice of parameters - recall particularly that $X(0)=20000$ in the base case - this means that the T/C-POP will be slightly in-the-money at issuance since $V^{\operatorname{ship}}(X(0), 0 ; \bar{T})=104.176 \mathrm{~m}$ (see table 3). The last-minute strike price, $K(5)$, is set equal to $E_{0}^{Q}\left\{V^{\text {ship }}(X(5), 5 ; \bar{T})\right\}$.

In figure 4 we first plot some examples of the critical freight rate curve which separates the state space into an exercise region (above) and a continuation region (below). This curve is plotted for four different values of the contracted fixed T/C rate, $\bar{X}$, which must be paid until 


\section{Critical freight rate curves for pure American TCPOP Exercise region above, continuation region below curve}

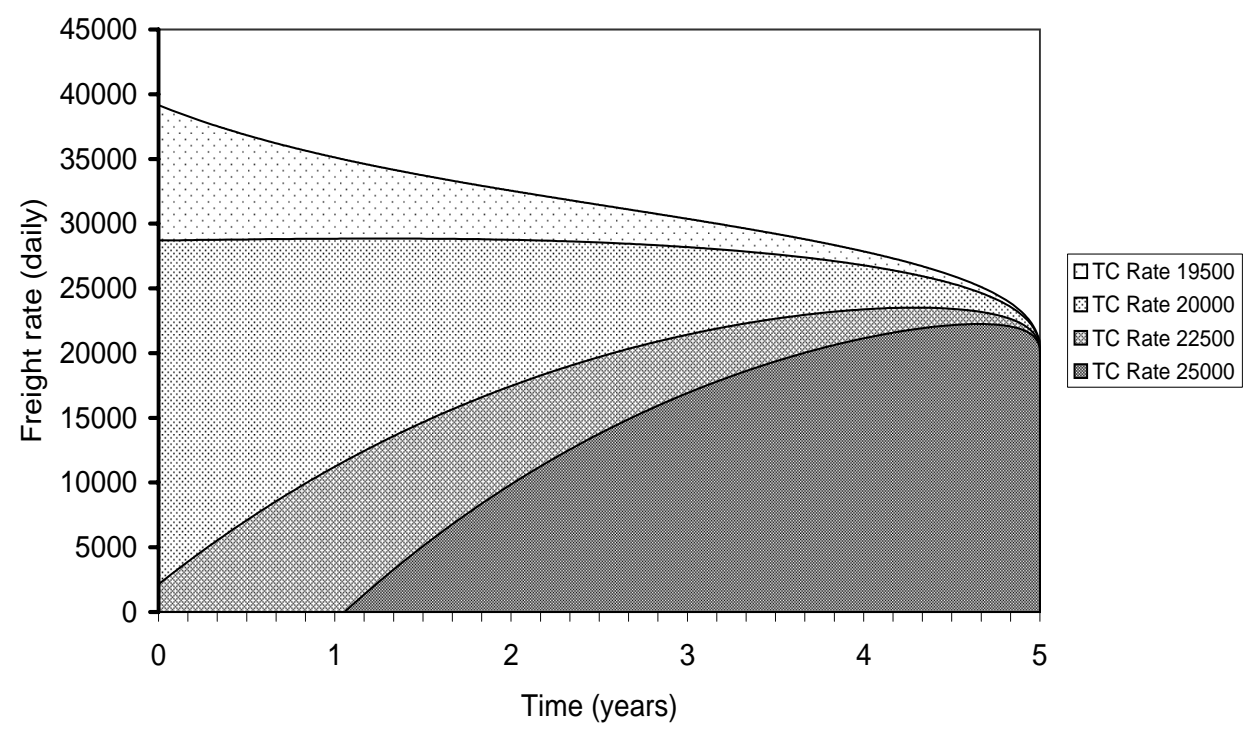

Figure 4: $\kappa=0.25, r=0.05, T=5, \bar{T}=25, \bar{V}=5 \mathrm{~m}, \theta^{*}=20000, \sigma=5000$, strike price function linear between $K(0)=102 \mathrm{~m}$ and $K(5)=92.865 \mathrm{~m}$.

the purchase option is exercised or the contract expires. We note that the plot reveals that for the two highest contracted T/C rates, the American-style T/C-POP should be optimally exercised immediately, ie. at $t=0$, for (almost) all values of the current spot freight rate. In other words, it is profitable to strike an out-of-the-money option in order to get rid of a very expensive lease contract in these cases. For lower contracted T/C rates the contract holder should be more patient. We see that spot rates should increase to almost 40000 per day (remember that the long run mean is 20000 per day) before a T/C-POP holder with lease payments of $\bar{X}=19500$ should terminate this relatively favorable lease at $t=0$ and buy the ship. Note finally that the curves converge to the same point at $t=5$ which defines the level of the spot freight rate where $V^{\text {ship }}(X(5), 5 ; \bar{T})=K(5)$ regardless of the fixed T/C payment in the expiring lease contract.

Table 6 contains values of pure American-style T/C-POPs in the base case but for varying spot freight rates and varying contracted T/C rates. The values of the otherwise identical European contracts are provided in parentheses below the American contract values. 
Table 6:

Value of time charter contract with American-style purchase option (in millions)

(Value of similar European-style contract in parentheses below)

$$
r=5 \%, \kappa=0.25, \theta^{*}=20000 \text { per day, } \sigma=5,000 \text { per day }
$$

$$
t=0, T=5, \bar{T}=25, \bar{V}=5 \mathrm{~m}
$$

\begin{tabular}{|c|c|c|c|c|c|c|}
\hline & \multicolumn{5}{|c|}{ Contracted daily T/C rate, $\bar{X}$} \\
\hline & & 19500 & 20000 & 22500 & 25000 & 30000 \\
\hline \multirow{6}{*}{$X(0)$} & 5000 & $\begin{array}{c}-12.151 \\
(-12.180)\end{array}$ & $\begin{array}{c}-12.927 \\
(-12.977)\end{array}$ & $\begin{array}{c}-15.814 \\
(-16.958)\end{array}$ & $\begin{array}{c}-15.814 \\
(-20.940)\end{array}$ & $\begin{array}{c}-15.814 \\
(-28.903)\end{array}$ \\
\hline & 10000 & $\begin{array}{c}-7.073 \\
(-7.120)\end{array}$ & $\begin{array}{c}-7.835 \\
(-7.916)\end{array}$ & $\begin{array}{c}-9.818 \\
(-11.898)\end{array}$ & $\begin{array}{c}-9.818 \\
(-15.879)\end{array}$ & $\begin{array}{c}-9.818 \\
(-23.843)\end{array}$ \\
\hline & 15000 & $\begin{array}{c}-1.883 \\
(-1.957)\end{array}$ & $\begin{array}{c}-2.619 \\
(-2.753)\end{array}$ & $\begin{array}{c}-3.821 \\
(-6.735)\end{array}$ & $\begin{array}{c}-3.821 \\
(-10.716)\end{array}$ & $\begin{array}{c}-3.821 \\
(-18.680)\end{array}$ \\
\hline & 20000 & $\begin{array}{c}3.431 \\
(3.316)\end{array}$ & $\begin{array}{c}2.747 \\
(2.520)\end{array}$ & $\begin{array}{c}2.176 \\
(-1.462)\end{array}$ & $\begin{array}{c}2.176 \\
(-5.444)\end{array}$ & $\begin{array}{c}2.176 \\
(-13.407)\end{array}$ \\
\hline & 25000 & $\begin{array}{c}8.880 \\
(8.701)\end{array}$ & $\begin{array}{c}8.306 \\
(7.905)\end{array}$ & $\begin{array}{c}8.173 \\
(3.923)\end{array}$ & $\begin{array}{c}8.173 \\
(-0.059)\end{array}$ & $\begin{array}{c}8.173 \\
(-8.022)\end{array}$ \\
\hline & 30000 & $\begin{array}{c}14.474 \\
(14.196)\end{array}$ & $\begin{array}{c}14.169 \\
(13.399)\end{array}$ & $\begin{array}{l}14.169 \\
(9.418)\end{array}$ & $\begin{array}{l}14.169 \\
(5.436)\end{array}$ & $\begin{array}{c}14.169 \\
(-2.527)\end{array}$ \\
\hline
\end{tabular}

Strike price, $K(t)$, linear between $K(0)=102.000 \mathrm{~m}$ and $K(5)=92.865 \mathrm{~m}$

From table 6 it may be noted that the American contract values are always at least as high as their European counterparts as they also must be. Second, we see that the values react as expected to changes in $\bar{X}$ and $X(0)$. The values generally increase as $\bar{X}$ falls and as $X(0)$ rises, but note that for the American contract the value is insensitive to lowering $\bar{X}$ until the critical freight rate is reached the reason being that the American contract should be optimally exercised anyway for these combinations of $\bar{X}$ and $X(0)$. Third, it can be observed that even Americanstyle contracts can have a negative value. This is because even though with the American type contract it is possible to terminate an unfavorable lease contract prematurely, the "price" of this transaction is that the T/C-POP holder must buy an overpriced ship. Note finally that the value of the option to exercise prematurely can be of highly significant value. Valuation methods that do not take the American exercise feature explicitly into account may thus lead to highly misleading results. 
Having illustrated some basic properties of the pure American type T/C-POP we now move on to considering some actual contracts from practice.

\subsection{Case 1: Time charter with Bermudan purchase option}

As our first practical case we will consider a T/C-POP that was described by the Norwegian shipping firm Golden Ocean Group Ltd. in a news release on February 6, 2007. ${ }^{6}$ The news release concerned transactions involving a total of four new Capesize vessels that were ordered from Daehan Shipyards in Korea by Golden Ocean in December 2006. ${ }^{7}$ According to the news release, two of the vessels had been "fixed out" on normal 5-year time charters without any options attached. These vessels were kept owned "for opportunistic trading" as the news release had it. But the other two vessels had been sold and leased back with purchase options in a deal with NYSE listed Ship Finance International Ltd. that was described in unusual detail in the news release: The vessels were "sold ... based on a total delivered price of USD 80 million". And as the news release further read: "Upon delivery from the shipyard, the vessels will commence 15 year bareboat contracts to Golden Ocean, and the charter rate per vessel is agreed as follows:

$$
\begin{array}{ll}
\text { Year 1-5: } & \text { USD 27,450 per day } \\
\text { Year 6-10: } & \text { USD 22,600 per day } \\
\text { Year 11-15: } & \text { USD 19,750 per day.” }
\end{array}
$$

Finally, the news release informed that "Golden Ocean has been granted fixed price purchase options for each of the vessels after 5, 10, and 15 years at USD 61 million, USD 44 million, and USD 24 million, respectively.”

By entering the contract described above Golden Ocean has clearly acquired a T/C-POP contract that is Bermudan-style since the purchase option can only be exercised at 3 distinct time points, namely after 5 years, 10 years, or after 15 years as also illustrated in the figure below.

\footnotetext{
${ }^{6}$ We found the news release on Prime Newswire, see e.g. www.primenewswire.com.

${ }^{7}$ Capesize vessels are dry bulk carriers of about 150,000 DWT or more. They are too large to traverse the Suez and Panama canals.
} 


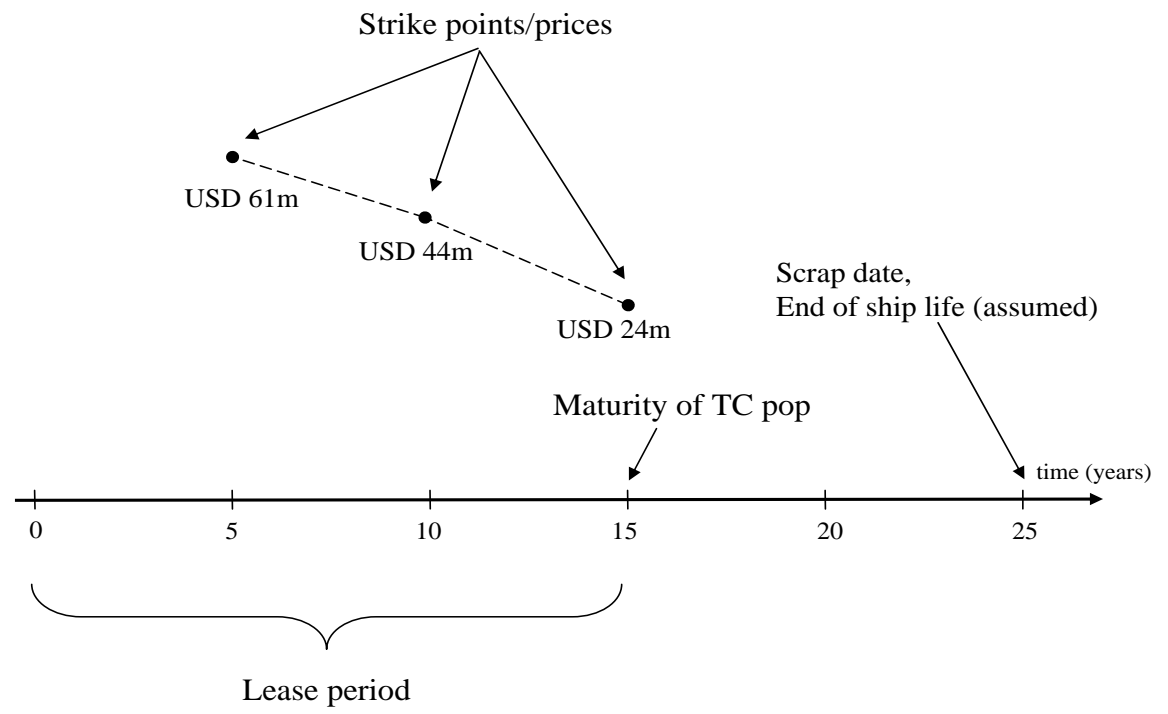

Figure 5: Structure of Golden Ocean’s Bermudan-style T/C-POP.

Golden Ocean's contract fits nicely into our model and numerical scheme. All necessary contract details are known and as soon as the necessary factor process and other market parameters have been estimated we can initiate the valuation procedure which would proceed as follows:

1. Initiate the valuation procedure at the back end of the grid (ie. at $t=T=15$ years) as before by determining the value of the purchase option at maturity for all values of the state variable. This value is of course given as the positive part of the ship value - which is a known function of the state variable - minus the strike price of USD 24 million. This analysis will also determine a critical freight rate level at $t=T=15$ years. This is the freight rate below which the option will be left unexercised.

2. The state dependent contract values at $t=10$ years can be obtained by moving the above mentioned array of terminal contract values backwards in time by way of the finite difference algorithm. However, since as seen from time $t=10$ the contract is a pure Europeanstyle contract, a faster and more accurate alternative is to use the previously derived closed form solutions to establish the continuation value of the contract at time $t=10$. The state dependent contract values (and the exercise policy) at time $t=10$ are then determined by comparing and choosing in each state the highest of the values of immediate exercise and continuation respectively. 
3. The state dependent contract values at the initial date $t=0$ is now found by moving the time $t=10$ array of contract values backwards in time using the finite difference algorithm. The algorithm should test for the possibility of optimal exercise at $t=5$.

Figure 6 and table 7 below contain some representative results from implementing this numerical scheme to the above-described contract. Since the purpose here is merely one of illustration, we have not attempted to obtain accurate estimates of our model parameters pertaining to the market for Capesize vessels in early 2007. Our first illustration in figure 6 below is therefore constructed using the same parameter values as in the previous example along with the actual contractually specified strike prices cf. above.

\section{Contract value funtions and net gains from early exercise} Case 1

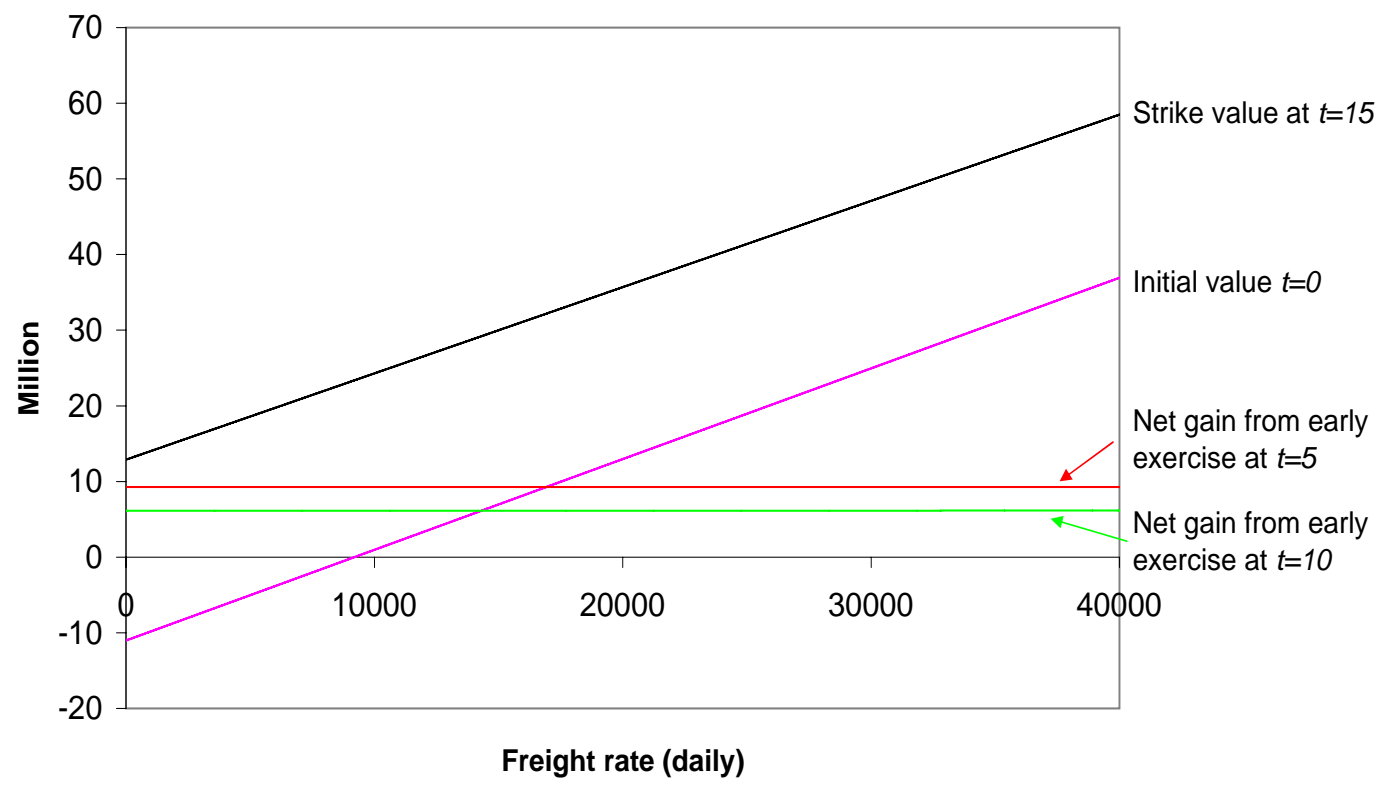

Figure 6: $\kappa=0.25, r=0.05, \bar{T}=25, \bar{V}=5 \mathrm{~m}, \theta^{*}=20000, \sigma=5000, K(5)=61 \mathrm{~m}$, $K(10)=44 \mathrm{~m}, K(15)=24 \mathrm{~m}$.

The positively sloped lines in figure 6 show the contract value at initiation $(t=0)$ and at expiration ( $t=15)$ as a function of the current spot freight rate. The contract value at expiration is given simply as $\left[V^{\text {Ship }}(X(15), 15 ; \bar{T})-K\right]^{+}$where $K=24 \mathrm{~m}$ and where as before it is assumed that $\bar{T}=25$. The plot indicates that the purchase option should be exercised for all positive spot freight rates at the terminal date. The final strike price of $24 \mathrm{~m}$ therefore appears very favorable 
for the present choice of parameters. However, and as we have seen before, the initial contract value can be negative when spot freight rates are sufficiently low (here below about 9000 per day) relative to contracted daily lease rates (here 20000 per day). This is of course explained by the lease rates which must be paid at least until the first exercise opportunity.

The horizontal lines in figure 6 show the difference between the exercise value and the continuation value at the intermediate strike dates $t=5$ and $t=10$. The fact that this net gain from early exercise is positive everywhere both for $t=5$ and for $t=10$ means that the purchase option is optimally exercised for certain at $t=5$. This is another indication that strike prices are very low for the particular choice of other parameters. This in turn also explains why the net gain is insensitive to the current spot freight rate: The very low strike prices essentially remove all optionality from the contract. The contract holder knows for sure that he will end up owning the ship and his decision problem becomes one of just determining the cheapest of three deterministic financing alternatives: leasing until $t=5$, or until $t=10$, or until $t=15$, and buying the ship thereafter.

\section{Contract value funtions and net gains from early exercise} Adjusted Case 1

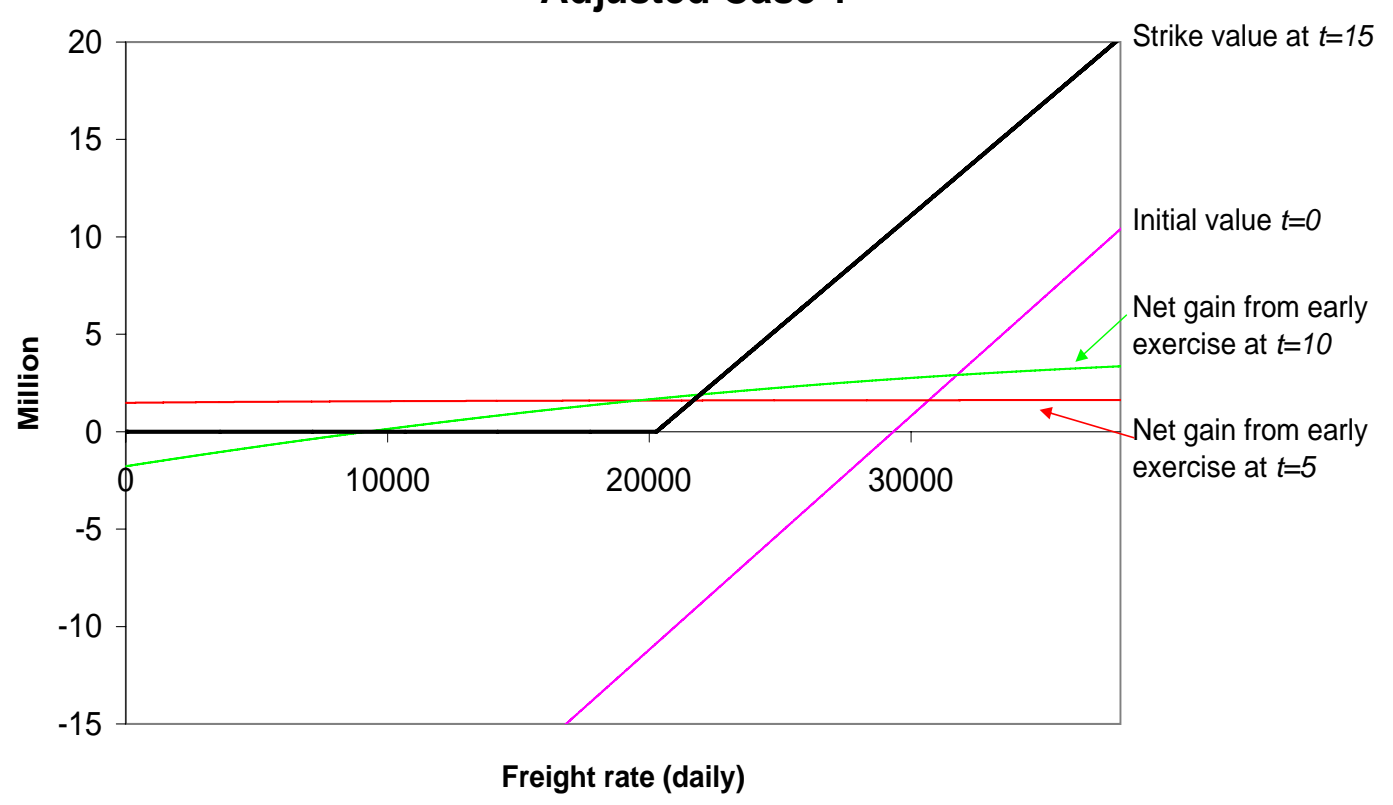

Figure 7: $\kappa=0.25, r=0.05, \bar{T}=25, \bar{V}=5 \mathrm{~m}, \theta^{*}=20000, \sigma=5000, K(5)=92.5 \mathrm{~m}$, $K(10)=74 \mathrm{~m}, K(15)=60 \mathrm{~m}$.

Figure 7 shows that if we increase the contract's three strike prices to $92.5 \mathrm{~m}, 74 \mathrm{~m}$, and 
$60 \mathrm{~m}$ respectively, then optionality is "restored" and the purchase option payoff function takes the familiar "kinked" piecewise linear form. It may be noted that spot freight rates must now be higher than 20000 per day in order for exercise to be optimal at maturity. At time $t=10$ the critical freight rate is about 10000 per day, whereas at time $t=5$ exercise is optimal for all values of the state variable. At the initial date the contract looks less attractive and the total value is negative for freight rates below about 29000 per day. This result is of course a consequence of the relatively high lease rate of 27450 per day which must be paid throughout the first 5-year period of the contract where premature exercise is not possible.

Returning to the base case with the actual strike prices, Table 7 contains some initial total contract values for different values of the current spot freight rate and the mean reversion parameter, and we have again included European contract values $(T=15)$ for comparison. The effects of changing the state variable, $X(0)$, and the mean reversion rate, $\kappa$, are as expected and we see again that a right to premature exercise - here Bermudan-style - can be very valuable.

\section{Table 7:}

\section{Value of Bermudan T/C-POP (in millions)}

(Value of similar European-style contract in parentheses below)

$$
\begin{gathered}
r=5 \%, \theta^{*}=20000 \text { per day, } \sigma=5,000 \text { per day } \\
t=0, \bar{T}=25, \bar{V}=5 \mathrm{~m}
\end{gathered}
$$

\begin{tabular}{|c|c|c|c|c|c|}
\hline & \multicolumn{4}{|c|}{ Mean reversion rate, $\kappa$} \\
\hline & & 0.25 & 0.50 & 0.75 & 1.00 \\
\hline \multirow{7}{*}{$X(0)$} & 5000 & $\begin{array}{c}-5.029 \\
(-15.970)\end{array}$ & $\begin{array}{c}3.142 \\
(-7.795)\end{array}$ & $\begin{array}{c}6.186 \\
(-4.709)\end{array}$ & $\begin{array}{c}7.545 \\
(-3.002)\end{array}$ \\
\hline & 10000 & $\begin{array}{c}0.967 \\
(-9.975)\end{array}$ & $\begin{array}{c}6.415 \\
(-4.528)\end{array}$ & $\begin{array}{c}8.459 \\
(-2.484)\end{array}$ & $\begin{array}{c}9.528 \\
(-1.413)\end{array}$ \\
\hline & 15000 & $\begin{array}{c}6.964 \\
(-3.979)\end{array}$ & $\begin{array}{c}9.688 \\
(-1.256)\end{array}$ & $\begin{array}{c}10.710 \\
(-0.234)\end{array}$ & $\begin{array}{l}11.245 \\
(0.301)\end{array}$ \\
\hline & 20000 & $\begin{array}{l}12.960 \\
(2.017)\end{array}$ & $\begin{array}{l}12.960 \\
(2.016)\end{array}$ & $\begin{array}{l}12.960 \\
(2.016)\end{array}$ & $\begin{array}{l}12.960 \\
(2.015)\end{array}$ \\
\hline & 25000 & $\begin{array}{c}18.957 \\
(8.014)\end{array}$ & $\begin{array}{l}16.233 \\
(5.289)\end{array}$ & $\begin{array}{l}15.209 \\
(4.265)\end{array}$ & $\begin{array}{l}14.673 \\
(3.729)\end{array}$ \\
\hline & 30000 & $\begin{array}{c}24.953 \\
(14.009)\end{array}$ & $\begin{array}{l}19.503 \\
(8.560)\end{array}$ & $\begin{array}{l}17.456 \\
(6.513)\end{array}$ & $\begin{array}{l}16.380 \\
(5.440)\end{array}$ \\
\hline & 35000 & $\begin{array}{c}30.947 \\
(20.003)\end{array}$ & $\begin{array}{c}22.759 \\
(11.822)\end{array}$ & $\begin{array}{l}19.603 \\
(8.709)\end{array}$ & $\begin{array}{c}17.386 \\
(6.844)\end{array}$ \\
\hline
\end{tabular}

Strike prices; $K(5)=61 \mathrm{~m}, K(10)=44 \mathrm{~m}, K(15)=24 \mathrm{~m}$ 


\subsection{Case 2: American-style T/C-POP with lock-up period and extension options}

Our second example inspired by practice is a T/C-POP contract agreed between Danish shipping firm D/S Norden and a Japanese shipyard on March 2, 2004. ${ }^{8}$ The contract involves a 5-year extendable lease of a new-built Panamax sized vessel with an American option to buy the ship after an initial 3-year lock-up period, cf. figure $7 .^{9}$

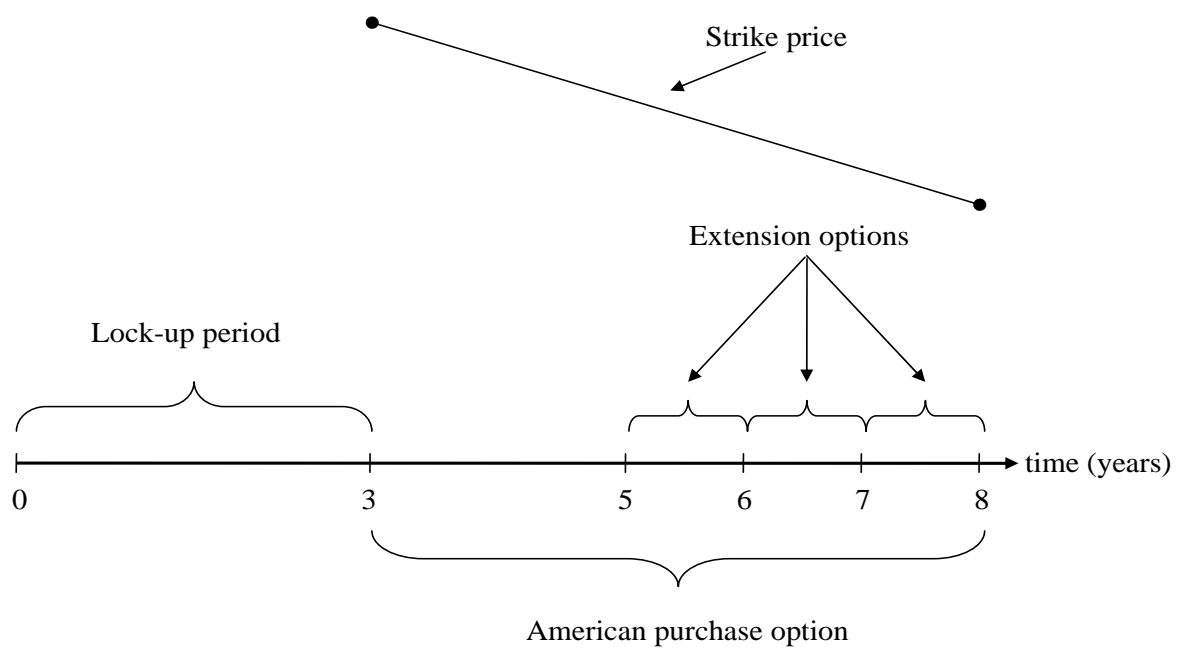

Figure 8: Structure of D/S Norden's complex T/C-POP.

The details of the lease payments are expressed as follows in the contract: "Time Charter

\footnotetext{
${ }^{8} \mathrm{D} / \mathrm{S}$ Norden kindly provided us with a copy of the original contract, but has requested that the names of their contract counterpart and of the vessel in question are not disclosed here.

${ }^{9}$ Panamax sized vessels are (typically bulk carriers) designed to fit the locks of the Panama Canal (max width of $32.21 \mathrm{~m}$ and max length of $289.5 \mathrm{~m}$ ). The displacement is around $60,000-80,000$ DWT.
} 
hire to be paid at the rate herebelow per day or pro rata including overtime;

$$
\begin{array}{ll}
1^{\text {st }} \text { year } & \text { USD15,000 per day including overtime } \\
2^{\text {nd }} \text { year } & \text { USD15,000 per day including overtime } \\
3^{\text {rd }} \text { year } & \text { USD11,000 per day including overtime } \\
4^{\text {th }} \text { year } & \text { USD10,000 per day including overtime } \\
5^{\text {th }} \text { year } & \text { USD10,000 per day including overtime } \\
6^{\text {th }} \text { year (Optional Period) } & \text { USD13,000 per day including overtime } \\
7^{\text {th }} \text { year (Optional Period) } & \text { USD13,500 per day including overtime } \\
8^{\text {th }} \text { year (Optional Period) } & \text { USD14,000 per day including overtime.” }
\end{array}
$$

In relation to the purchase option the contract specifies that "Charterers have the option to purchase the Vessel after the end of the $3^{\text {rd }}$ year and at any time during any optional year, if the extend charter period is exercised ... The purchase prices at which Charterers buy the Vessel under this Agreement are as follows:

$\begin{array}{ll}\text { At the end of } 3^{\text {rd }} \text { year } & \text { JPY2.70 Billion } \\ \text { At the end of } 4^{\text {th }} \text { year } & \text { JPY2.57 Billion } \\ \text { At the end of } 5^{\text {th }} \text { year } & \text { JPY2.44 Billion } \\ \text { At the end of } 6^{\text {th }} \text { year (Optional Period) } & \text { JPY2.31 Billion } \\ \text { At the end of } 7^{\text {th }} \text { year (Optional Period) } & \text { JPY2.18 Billion } \\ \text { At the end of } 8^{\text {th }} \text { year (Optional Period) } & \text { JPY2.05 Billion” }\end{array}$

Finally, the contract states that simple linear interpolation is to be applied between the nearest two of the above mentioned strike prices "if Charterers exercise their option to purchase the Vessel at any time other that at the end of respective year...”.

A few comments on the contract details are in order at this point. Let us first emphasize that we interpret the contract such that the ship must be leased for at least three years. After 3 years and until the end of the fifth year the lease can be terminated only by exercising the option to buy the ship. If the purchase option has not been exercised after 5 years the charterer can at this date; 1) stop the lease entirely ("exit”), 2) buy the ship ("exercise"), or 3) declare that he wishes to extend the lease for another year ("continue"). If the lease is thus extended the American option to buy the ship (and terminate the lease) at any time is kept alive. This 1-year extension option also applies after the 6th and 7th year. 
It should also be noted that the exercise prices are expressed in Japanese Yen (JPY). Since future exchange rates are uncertain this introduces another source of risk that should ideally be taken into account in valuation. However, in the numerical examples we present below we have chosen to ignore this fact in the interest of simplicity and simply converted the JPY exercise prices into USD equivalents using a constant exchange rate. Ignoring the volatility in the USD/JPY exchange rate should bias our option values downwards.

The numerical valuation procedure will proceed as follows:

1. The contract is first valued at its final expiration date at $t=8$ years. The value is equal to the max of 0 (stop) and the intrinsic value of the purchase option. The latter is expressed in closed form for all freight rates as before.

2. We work backwards from time $t=8$ to $t=7$ using the finite difference algorithm. In each step we check for optimal premature exercise of the American purchase option. When $t=7$ is reached the contract value in each state is set equal to the max of 0 (stop entirely), the value of immediate exercise of the purchase option (expressed in closed form), and the continuation value (obtained via the finite difference algorithm).

3. The transformation of values from $t=7$ to $t=6$, and from $t=6$ to $t=5$ is done by following the exact same procedure as in 2 .

4. From $t=5$ we work backwards until time $t=3$ checking in each step for optimal early exercise of the American purchase option. In this time interval the lease cannot be stopped without exercising the option.

5. From time $t=3$ we work backwards until the initial date $t=0$ by way of the finite difference algorithm. In this time interval the lease cannot be stopped and the option cannot be exercised.

Figures 9 and 10 have been generated using the above-described procedure. They show some examples of the shape of the optimal exercise and continuation regions for the extendable T/C-POP that was introduced above. Since the underlying asset is now a significantly smaller ship than in the previous case (cf. footnotes 5 and 7) we have adjusted the model parameters somewhat, and we now use $\theta^{*}=9000$ per day, $\kappa=0.25, \sigma=3000$ per day, $\bar{V}=1000000$, $\bar{T}=25$, and $r=0.05$. These parameter values imply an initial ship value of around 41.5 million 
which is in fine line with the April 2004 Panamax newbuilding prices of USD 41 million reported by Clarkson's databases. ${ }^{10}$ The spot USD/JPY exchange rate was around 110 (Yen per Dollar) in March 2004, so we use this as our base exchange rate. This means, for example, that K(3) = JPY 2.70 billion = USD 24.55 million, and K(8) = JPY 2.05 billion = USD 18.64 million. These strike prices appear quite low - and therefore quite favorable for the T/C-POP holder compared with model-expected ship values of 37.7 million and 34.6 million after 5 and 8 years respectively, and we have therefore also performed calculations with an alternative strike curve where all strike prices have been increased by JPY 1.7 billion. In addition, we have performed calculations with alternative exchange rates, cf. table 8 below.

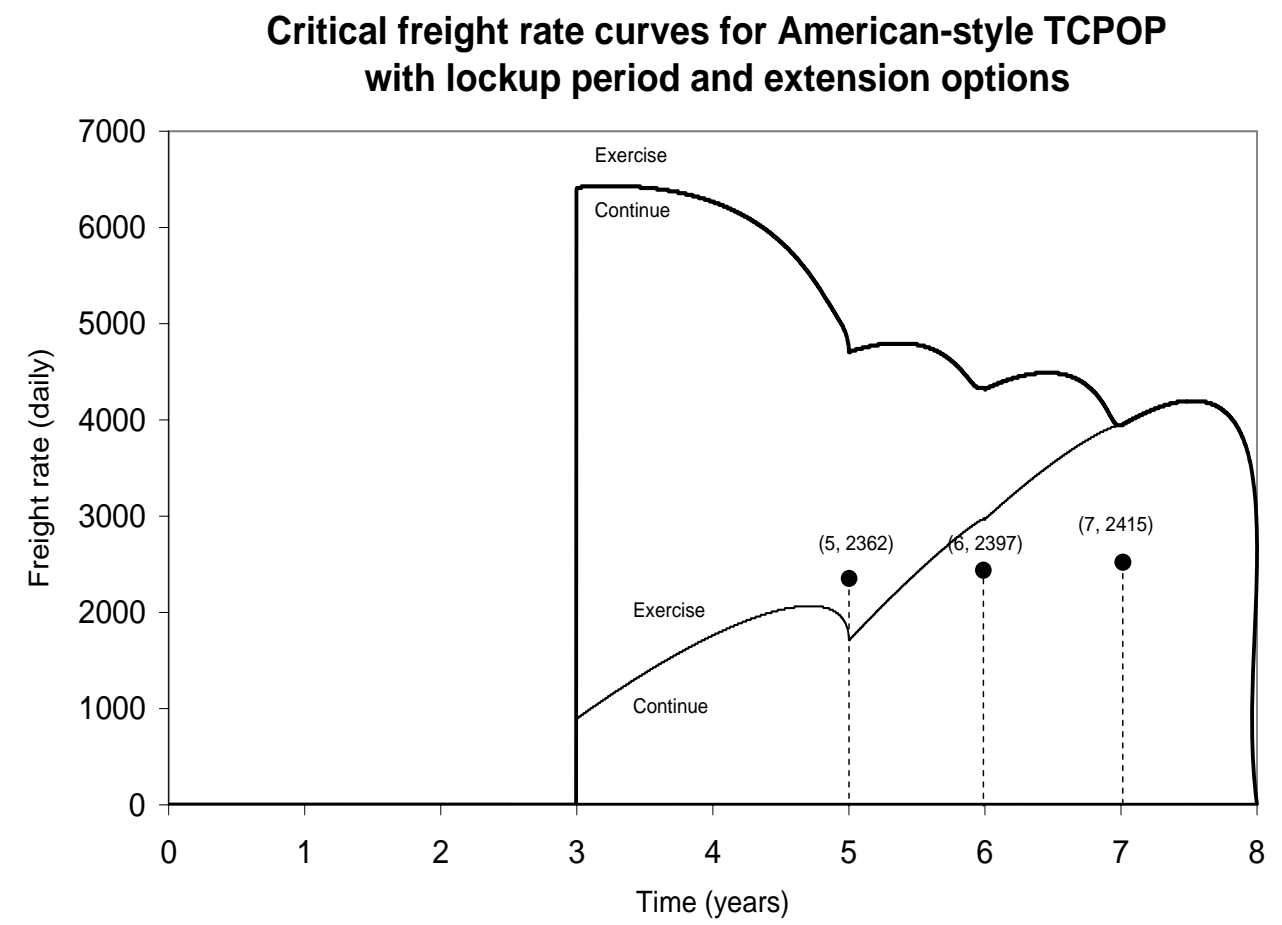

Figure 9: $\kappa=0.25, r=0.05, \bar{T}=25, \bar{V}=1 \mathrm{~m}, \theta^{*}=9000, \sigma=3000$, strike price function linear between $K(3)=24.55 \mathrm{~m}$ and $K(8)=18.64 \mathrm{~m}$.

Figure 9 contains two curves in $(t, X(t))$ space. The upper curve is the set of critical freight rates which separates the continuation region (below) and the exercise region (above). The curve is continuous but has three non-differentiability points at $t=5, t=6$, and $t=7$ where lease payments change and where the lease can be stopped. The second and lower curve has been included for illustrative purposes. It shows critical freight rates in relation to a modified 8-year

\footnotetext{
${ }^{10}$ For more see e.g. www.clarksons.com.
} 
contract (but otherwise identical to the true contract) where the options to extend/quit at $t=5$, $t=6$, and $t=7$ have been removed. The purchase option is thus purely American from the end of year 3 to the end of year 8 . In this case we see that the contract will always be exercised earlier - that is, the contract holder is less patient - than when extension options are present. It is quite natural that the exercise strategy is more conservative when there is less flexibility.

Returning to the original contract with the 3 consecutive extension options the figure also illustrates three critical "stopping points" at $t=5, t=6$, and $t=7$. If the freight rate is below the given critical values at these dates, it is optimal to terminate the contract entirely.

\section{Critical freight rate curves for American-style TCPOP with lockup period and extension options (Displaced strike price function)}

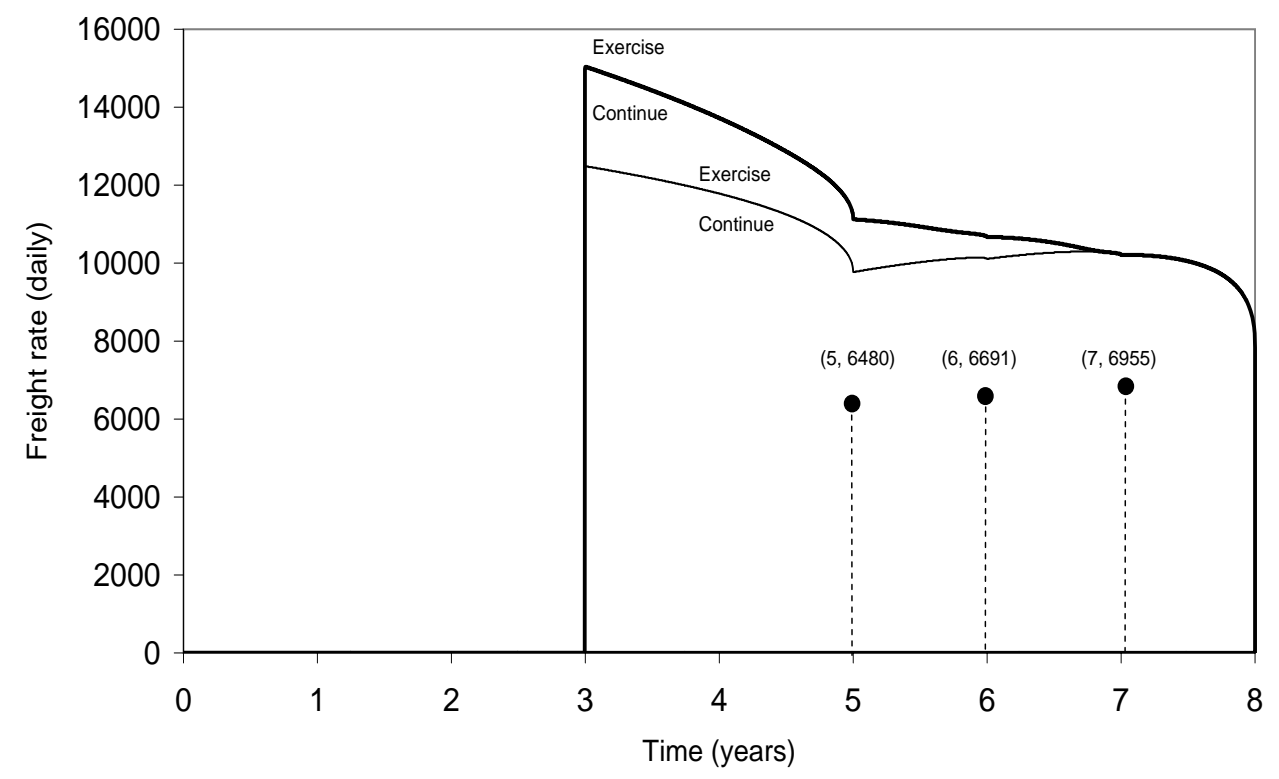

Figure 10: $\kappa=0.05, r=0.05, \bar{T}=25, \bar{V}=1 \mathrm{~m}, \theta^{*}=9000, \sigma=3000$, strike price function linear between $K(3)=40.00 \mathrm{~m}$ and $K(8)=34.09 \mathrm{~m}$.

In general, the critical freight rates in figure 9 are quite low compared with our (risk neutral) mean reversion level of 9000 per day. This mirrors the earlier mentioned fact that contractual strike prices seem favorable compared with the initial ship value which as already argued is quite realistic. A partial "repair" of this effect is obtained if we raise strike prices to be more in accordance with expected future ship values. This is done in figure 10 where all contractual strike prices are raised by 1.7 billion and everything else is as in figure 9 . The effect of this is to raise both critical freight rate curves and we see, for example, that the freight rate must now 
increase to about 15000 per day in order for the purchase option to be optimally exercised at $t=3$.

Table 8 provides examples of total contract values for the currently considered contract. We have computed T/C-POP values at time 0 for different values of the initial freight rate, for three different values of the constant USD/JPY exchange rate, and for both the actual and the displaced strike price functional, cf. earlier. Each entry of the table contains two values: One with and one without (in parentheses below) taking the extension/exit options into account.

\section{Table 8:}

\begin{tabular}{|c|c|c|c|c|c|c|c|}
\hline & $r=5$ & $\begin{array}{l}\text { ue of Comp } \\
\text { Value withos } \\
, \kappa=0.05 \text {, }\end{array}$ & $\begin{array}{l}\text { ex America } \\
\text { extension } \\
*=9000\end{array}$ & $\begin{array}{l}\text { 1-style } \mathrm{T} / \mathrm{C} \\
\text { pption in } \\
=3000\end{array}$ & $\begin{array}{l}\text {-POP (in m } \\
\text { rentheses b } \\
=0, \bar{T}=2\end{array}$ & $\begin{array}{l}\text { lions) } \\
\text { low) } \\
\bar{V}=1 \mathrm{~m}\end{array}$ & \\
\hline & & Actua & strike func & tion & Displ & ced strike fu & action \\
\hline & & & & & /JPY & & \\
\hline & & 100 & 110 & 120 & 100 & 110 & 120 \\
\hline & 2500 & $\begin{array}{c}-7.843 \\
(-11.186)\end{array}$ & $\begin{array}{c}-6.666 \\
(-9.418)\end{array}$ & $\begin{array}{l}-5.570 \\
(7.841)\end{array}$ & $\begin{array}{c}-12.773 \\
(-19.005)\end{array}$ & $\begin{array}{l}-12.120 \\
(-17.950)\end{array}$ & $\begin{array}{c}-11.392 \\
(-16.766)\end{array}$ \\
\hline & 5000 & $\begin{array}{c}-1.307 \\
(-3.344)\end{array}$ & $\begin{array}{c}0.161 \\
(-1.413)\end{array}$ & $\begin{array}{c}1.489 \\
(0.262)\end{array}$ & $\begin{array}{c}-8.017 \\
(-12.798)\end{array}$ & $\begin{array}{c}-7.040 \\
(-11.388)\end{array}$ & $\begin{array}{l}-5.985 \\
(-9.849)\end{array}$ \\
\hline & 7500 & $\begin{array}{c}5.819 \\
(4.702)\end{array}$ & $\begin{array}{c}7.534 \\
(6.732)\end{array}$ & $\begin{array}{c}9.045 \\
(8.458)\end{array}$ & $\begin{array}{l}-2.741 \\
(-6.233)\end{array}$ & $\begin{array}{l}-1.375 \\
(-4.432)\end{array}$ & $\begin{array}{c}0.051 \\
(-2.534)\end{array}$ \\
\hline Freight rate & 10000 & $\begin{array}{c}13.412 \\
(12.867)\end{array}$ & $\begin{array}{c}15.308 \\
(14.948)\end{array}$ & $\begin{array}{c}16.942 \\
(16.696)\end{array}$ & $\begin{array}{c}3.115 \\
(0.701)\end{array}$ & $\begin{array}{c}4.906 \\
(2.900)\end{array}$ & $\begin{array}{c}6.713 \\
(5.124)\end{array}$ \\
\hline$X(0)$ & 12500 & $\begin{array}{c}21.325 \\
(21.092)\end{array}$ & $\begin{array}{c}23.335 \\
(23.194)\end{array}$ & $\begin{array}{c}25.040 \\
(24.951)\end{array}$ & $\begin{array}{c}9.555 \\
(7.986)\end{array}$ & $\begin{array}{c}11.772 \\
(10.557)\end{array}$ & $\begin{array}{c}13.926 \\
(13.043)\end{array}$ \\
\hline & 15000 & $\begin{array}{c}29.428 \\
(29.341)\end{array}$ & $\begin{array}{c}31.498 \\
(31.450)\end{array}$ & $\begin{array}{c}33.328 \\
(33.210)\end{array}$ & $\begin{array}{c}16.532 \\
(15.579)\end{array}$ & $\begin{array}{c}19.135 \\
(18.465)\end{array}$ & $\begin{array}{c}21.572 \\
(21.132)\end{array}$ \\
\hline & 17500 & $\begin{array}{c}37.627 \\
(37.599)\end{array}$ & $\begin{array}{c}39.724 \\
(39.710)\end{array}$ & $\begin{array}{c}41.478 \\
(41.470)\end{array}$ & $\begin{array}{c}23.957 \\
(23.421)\end{array}$ & $\begin{array}{c}26.874 \\
(26.542)\end{array}$ & $\begin{array}{c}29.511 \\
(29.318)\end{array}$ \\
\hline & 20000 & $\begin{array}{c}45.867 \\
(45.859)\end{array}$ & $\begin{array}{c}47.975 \\
(47.971)\end{array}$ & $\begin{array}{c}49.733 \\
(49.731)\end{array}$ & $\begin{array}{c}31.718 \\
(31.441)\end{array}$ & $\begin{array}{c}34.865 \\
(34.718)\end{array}$ & $\begin{array}{c}37.625 \\
(37.550)\end{array}$ \\
\hline
\end{tabular}

Contract values are seen to behave in accordance with intuition: They increase in $X(0)$ and in the USD/JPY exchange rate, and they decrease when the strike price function is displaced upwards. ${ }^{11}$

\footnotetext{
${ }^{11}$ Note that an increase in the USD/JPY (Yen-for-Dollar) exchange rate implies a lower strike price in dollar
} 
The option to extend the lease is more valuable for intermediate freight rates, ie. when freight rates are neither high enough to imply immediate exercise of the purchase option nor so low that the contract should be terminated.

\section{Concluding Remarks}

This paper has introduced, priced and analyzed various forms of Time Charters with Purchase Options which is a common type of lease contract in shipping markets. The challenge in valuing T/C-POPs is to deal with the embedded options in a consistent manner. For this purpose we set up a single-factor continuous time model for the stochastic dynamics of the spot freight rate which is the main risk factor and determinant for values of most shipping derivatives. The fundamental freight rate model was borrowed from Bjerksund and Ekern (1995) and it specifies freight rates as evolving according to the mean reverting Gaussian Ornstein-Uhlenbeck process. This process is well-known in the economics literature, it has been successfully applied in many other finance related aspects, and it has previously received some empirical support in relation to the modeling of the dynamics of freight rates in shipping markets.

Having described the dynamics of freight rates we applied standard contingent claims pricing techniques to establish values of simple freight rate derivatives in closed form. A closed form valuation formula was also derived for the simple European-style T/C-POP. For dealing with more complex Bermudan- and American-style T/C-POPs we devised a finite difference algorithm and illustrated its implementation with a host of numerical examples. During the course of this analysis we priced two recent examples of T/C-POPs from practice. One of these also contained a sequence of abandonment and extension options. It was documented that the various exotic exercise features could account for a significant part of the total value of T/C-POPs and that knowledge of (how to establish) optimal exercise strategies therefore is of vital importance.

Our analysis has some limitations and there are therefore some obvious directions for future research. First, although we argued that mean reversion is supported in freight rate data, the Ornstein-Uhlenbeck process admittedly also has some less desirable properties. It implies future freight rates that are Gaussian although actual freight rates often appear to be skewed, it has a constant rate of volatility although some empirical research (e.g. Adland (2000)) has found evidence of a volatility rate that increases with the level of freight rates, and it implies a positive terms. 
probability of negative freight rates at any future point in time (although this probability is usually negligible). To alleviate the above-mentioned deficiencies, Tvedt (1997) has proposed the Geometric Mean Reversion process as an alternative to the Ornstein-Uhlenbeck process and it would indeed be an interesting subject for future research to investigate the use of this and other alternative processes in pricing T/C-POPs and other freight rate derivatives.

Another possible area for future research would be to develop multi-factor models in order to be able to deal explicitly with additional risk factors such as stochastically varying exchange rates (as would have been appropriate in our Case 2), interest rates, market demand of transportation, as well as bunker oil prices and other factors of potential significance for the value of T/C-POP contracts. 


\section{These appendices are supplied for the referee's convenience The paper can be published with or without them}

\section{A Derivation of the fundamental partial differential equation}

The riskless interest rate, $r$, is assumed constant and the single factor (freight rate) process is given as

$$
d X(t)=\kappa(\theta-X(t)) d t+\sigma d \mathcal{W}(t)
$$

where $\mathcal{W}(\cdot)$ is a standard Wiener process under the "true" probability measure, $P$. Using arguments along the lines of e.g. Vasicek (1977) it can be shown that "derivatives” prices, $V(X, t)$, influenced by this factor and time must have dynamics described by

$$
\frac{d V(X, t)}{V(X, t)}=\left(r+\lambda(\cdot) \sigma_{V}\right) d t+\sigma_{V} d \mathcal{W}(t)
$$

where

$$
\sigma_{V}=\sigma \frac{V_{x}(X, t)}{V(X, t)}
$$

and where $\lambda(X, t)$ is the "market price of freight rate risk".

Now Girsanov's theorem tells us that we can perform a change of probability measure by defining

$$
d \mathcal{W}^{Q}(t)=d \mathcal{W}(t)+\lambda(\cdot) d t
$$

where $W^{Q}(\cdot)$ is now a standard Wiener process under the equivalent probability measure $Q$.

We will assume that $\lambda$ is constant. Then

$$
\begin{aligned}
\frac{d V(X, t)}{V(X, t)} & =\left(r+\lambda \sigma_{V}\right) d t+\sigma_{V}\left(d \mathcal{W}^{Q}(t)-\lambda d t\right) \\
& =r d t+\sigma_{V} d \mathcal{W}^{Q}(t) .
\end{aligned}
$$


The factor process under $Q$ is therefore given as

$$
\begin{aligned}
d X(t) & =\kappa(\theta-X(t)) d t+\sigma\left(d \mathcal{W}^{Q}(t)-\lambda d t\right) \\
& =[\kappa(\theta-X(t))-\sigma \lambda] d t+\sigma d \mathcal{W}^{Q}(t) \\
& =\left[\kappa\left(\theta-\frac{\sigma \lambda}{\kappa}-X(t)\right)\right] d t+\sigma d \mathcal{W}^{Q}(t) \\
& =\kappa\left(\theta^{*}-X(t)\right) d t+\sigma d \mathcal{W}^{Q}(t),
\end{aligned}
$$

where we have defined $\theta^{*}=\theta-\frac{\sigma \lambda}{\kappa}$.

Using Ito's lemma we can now characterize the dynamics of the $V$-process under $Q$ :

$$
\begin{aligned}
d V(X, t) & =V_{t} d t+V_{x} d X+\frac{1}{2} V_{x x}(d X)^{2} \\
& =\left\{V_{t}+\kappa\left(\theta^{*}-X(t)\right) V_{x}+\frac{1}{2} \sigma^{2} V_{x x}\right\} d t+\sigma V_{x} d \mathcal{W}^{Q}(t)
\end{aligned}
$$

Absence of arbitrage requires

$$
\begin{aligned}
\frac{d V(X, t)}{V(X, t)} & =\left\{\frac{V_{t}+\kappa\left(\theta^{*}-X(t)\right) V_{x}+\frac{1}{2} \sigma^{2} V_{x x}}{V}\right\} d t+\sigma \frac{V_{x}}{V} d \mathcal{W}^{Q}(t) \\
& =(r-\delta(t)) d t+\sigma \frac{V_{x}}{V} d \mathcal{W}^{Q}(t)
\end{aligned}
$$

where $\delta(t)$ is dividend rate received by claim. Introducing $\Gamma(t)=\delta(t) V(t)$ as the absolute cash flow from the claim we finally conclude that $V(\cdot)$ must satisfy

$$
V_{t}+\kappa\left(\theta^{*}-X(t)\right) V_{x}+\frac{1}{2} \sigma^{2} V_{x x}-(r-\delta(t)) V=0,
$$

or, equivalently,

$$
V_{t}+\kappa\left(\theta^{*}-X(t)\right) V_{x}+\frac{1}{2} \sigma^{2} V_{x x}-r V+\Gamma(t)=0 .
$$

This is the partial differential equation that is solved using finite difference methodology in the paper's numerical section. 


\section{B The Value of a European Option to Buy a Ship}

\section{B.1 Derivation of formula (20)}

Define first

$$
\begin{gathered}
\overline{\bar{K}}=\frac{K+\theta^{*}(A(\bar{T}-T, r+\kappa)-A(\bar{T}-T, r))-e^{-r(\bar{T}-T)} \bar{V}}{A(\bar{T}-T, r+\kappa)}, \\
m_{t, T}=E_{t}^{Q}\{X(T)\}=X(t) e^{-\kappa(T-t)}+\theta^{*}\left(1-e^{-\kappa(T-t)}\right), \\
v_{t, T}^{2}=\operatorname{Var}_{t}^{(Q)}\{X(T)\}=\frac{\sigma^{2}}{2 \kappa}\left(1-e^{-2 \kappa(T-t)}\right)
\end{gathered}
$$

and

$$
\xi=\frac{m_{t, T}-\overline{\bar{K}}}{v_{t, T}} .
$$

Then consider

$$
\begin{aligned}
& V^{\operatorname{Ship}}(X(T), T ; \bar{T})-K \\
= & \left(X(T)-\theta^{*}\right) A(\bar{T}-T, r+\kappa)+\theta^{*} A(\bar{T}-T, r)+e^{-r(\bar{T}-T)} \bar{V}-K \\
= & X(T) A(\bar{T}-T, r+\kappa)+\theta^{*}(A(\bar{T}-T, r)-A(\bar{T}-T, r+\kappa))+e^{-r(\bar{T}-T)} \bar{V}-K \\
= & A(\bar{T}-T, r+\kappa)\left[X(T)-\frac{K+\theta^{*}(A(\bar{T}-T, r+\kappa)-A(\bar{T}-T, r))-e^{-r(\bar{T}-T)} \bar{V}}{A(\bar{T}-T, r+\kappa)}\right] \\
= & A(\bar{T}-T, r+\kappa)[X(T)-\overline{\bar{K}}] .
\end{aligned}
$$


Now, to evaluate $E_{t}^{Q}\left\{[X(T)-\overline{\bar{K}}]^{+}\right\}$consider

$$
\begin{aligned}
& \int_{\overline{\bar{K}}}^{\infty}(y-\overline{\bar{K}}) f(y) d y \\
= & \int_{\overline{\bar{K}}}^{\infty}(y-\overline{\bar{K}}) \frac{1}{\sqrt{2 \pi v_{t, T}^{2}}} e^{-\frac{1}{2}\left(\frac{y-m_{t, T}}{v_{t, T}}\right)^{2}} d y \\
= & \int_{-\xi}^{\infty}\left(x v_{t, T}+m_{t, T}-\overline{\bar{K}}\right) \frac{1}{\sqrt{2 \pi}} e^{-\frac{1}{2} x^{2}} d x \\
= & \left(m_{t, T}-\overline{\bar{K}}\right)(1-N(-\xi))+v_{t, T} \int_{-\xi}^{\infty} \frac{1}{\sqrt{2 \pi}} x e^{-\frac{1}{2} x^{2}} d x \\
= & \left(m_{t, T}-\overline{\bar{K}}\right) N(\xi)+v_{t, T} \int_{\xi^{2}}^{\infty} \frac{1}{2} \frac{1}{\sqrt{2 \pi}} e^{-\frac{1}{2} z} d z \\
= & \left(m_{t, T}-\overline{\bar{K}}\right) N(\xi)+v_{t, T}\left[-\frac{1}{\sqrt{2 \pi}} e^{-\frac{1}{2} z}\right]_{\xi^{2}}^{\infty} \\
= & v_{t, T}\left(\xi N(\xi)+\left[0+\frac{1}{\sqrt{2 \pi}} e^{-\frac{1}{2} \xi^{2}}\right]\right) \\
= & v_{t, T}(\xi N(\xi)+n(\xi)) .
\end{aligned}
$$

Finally, premultiplying with $A(\bar{T}-T, r+\kappa)$ times the discount factor gives the desired result. 


\section{Additional Detail on the Finite Difference Method}

We first define $X_{j}=X_{\min }+j \cdot \triangle X$ and $\Gamma^{i, j}=\Gamma\left(X_{j}, i \cdot \triangle t\right)$. In the interior points of the discretized $X$-axis, ie. for $j=1, \ldots, J-1$, we approximate the fundamental PDE given in (6) as follows

$$
\begin{aligned}
& \frac{C^{i+1, j}-C^{i, j}}{\triangle t}+\alpha\left[\kappa\left(\theta^{*}-X_{j}\right) D_{1}\left(C^{i, j}\right)+\frac{\sigma^{2}}{2} D_{2}\left(C^{i, j}\right)-r C^{i, j}+\Gamma^{i, j}\right]+ \\
& (1-\alpha)\left[\kappa\left(\theta^{*}-X_{j}\right) D_{1}\left(C^{i+1, j}\right)+\frac{\sigma^{2}}{2} D_{2}\left(C^{i+1, j}\right)-r C^{i+1, j}+\Gamma^{i+1, j}\right]=0,
\end{aligned}
$$

where $D_{1}\left(C^{i, j}\right)$ and $D_{2}\left(C^{i, j}\right)$ are the usual central approximations of the first and second order derivatives, respectively. Note that by setting $\alpha=1$ we obtain the implicit Euler discretization (which is first-order-accurate in the time direction), while setting $\alpha=1 / 2$ we recast the CrankNicolson method (which is second-order-accurate in the time direction).

Now, special attention has to be given at the boundaries, ie. for $j=0$ and $j=J$, since the mean reverting feature of the freight rate process causes our PDE to be convection dominated. That is, as $X(t)$ gets larger the convection term, $\kappa\left(\theta^{*}-X(t)\right)$, which is the function associated with the first derivative in the space dimension of the PDE, becomes extremely large compared to the diffusion term $\sigma^{2} / 2$, which is the function associated with the second derivative in the space direction. Roughly speaking this means that although formally parabolic the PDE behaves as if it was hyperbolic. Therefore, to avoid spurious oscillations it is desirable to not specify boundary conditions at the top and at the bottom of the discrete grid. We thus let the PDE be satisfied at the boundaries of the grid but instead of using the standard central approximation for the first and second derivatives of the value function we approximate them implicitly. More specifically, we use the following approximations for the first and second derivatives at $j=0, J$;

$$
\begin{gathered}
\frac{\partial C\left(X_{\min }, t\right)}{\partial X} \approx \frac{-C^{i, 2}+4 C^{i, 1}-3 C^{i, 0}}{2 \triangle X} \\
\frac{\partial^{2} C\left(X_{\min }, t\right)}{\partial X^{2}} \approx \frac{C^{i, 2}-2 C^{i, 1}+C^{i, 0}}{\triangle X^{2}} \\
\frac{\partial C\left(X_{\max }, t\right)}{\partial X} \approx \frac{-C^{i, J-2}+4 C^{i, J-1}+3 C^{i, J}}{2 \triangle X} \\
\frac{\partial^{2} C\left(X_{\max }, t\right)}{\partial X^{2}} \approx \frac{C^{i, J-2}-2 C^{i, J-1}+C^{i, J}}{\triangle X^{2}} .
\end{gathered}
$$

For further discussion and for derivation of the above approximations the reader is referred to Vetzal (1998). 


\section{References}

Adland, R. and K. Cullinane (2006): “The Non-linear Dynamics of Spot Freight Rates in Tanker Markets,” Transportation Research Part E, 42(3):211-224.

Adland, R. and S. Koekebakker (2007): "Ship Valuation Using Cross-Sectional Sales Data: A Multivariate Non-Parametric Approach,” Maritime Economics and Logistics, 9(2):105-118.

Adland, R. O. (2000): “A Non-parametric Model of the Timecharter-equivalent Spot Freight Rate in the Very Large Crude Carrier Market,” Working Paper, Centre for International Economics and Shipping, Norwegian School of Economics and Business Administration.

Alesii, G. (2005): “VaR in Real Options Analysis,” Review of Financial Economics, 14(34):189-208.

Arnold, L. (1992): Stochastic Differential Equations: Theory and Applications, Krieger Publishing Company, Malabar, Florida.

Bachelier, M. L. (1900): “Theorie de la Speculation,” 3eme serie, tome 17, pp. 21-86, Annales Scientifique de l’Ecole Normale Superieure.

Bjerksund, P. and S. Ekern (1995): “Contingent Claims Evaluation of Mean-Reverting Cash Flows in Shipping,” in Trigeorgis, L., editor, Real Options in Capital Investment: Models, Strategies, and Applications, pages 207-219. Preager.

Duffie, D. (2001): Dynamic Asset Pricing Theory, Princeton University Press, Princeton and Oxford, 3rd edition.

Goldenberg, D. H. (1991): “A Unified Method for Pricing Options on Diffusion Processes,” Journal of Financial Economics, 29(1):3-34.

Hull, J. C. (2006): Options, Futures, and other Derivatives, Prentice-Hall, Inc., 6th edition.

Kavussanos, M. G. and I. D. Visvikis (2006): Derivatives and Risk Management in Shipping, Witherbys Publishing, London, United Kingdom.

McConnell, J. J. and J. S. Schallheim (1983): "Valuation of Asset Leasing Contracts,” Journal of Financial Economics, 12(2):237-261. 
Trigeorgis, L. (1996): “Evaluating Leases with Complex Operating Options,” European Journal of Operations Research, 91(2):315-329.

Tvedt, J. (1997): “Valuation of VLCCs under Income Uncertainty,” Maritime Policy \& Management, 24(2):159-174.

Vasicek, O. (1977): “An Equilibrium Characterization of the Term Structure,” Journal of Financial Economics, 5:177-188.

Vetzal, K. R. (1998): “An improved finite difference approach to fitting the initial term structure,” The Journal of Fixed Income, 7:62-81. 


\section{Working Papers from Finance Research Group}

F-2008-05 Peter Løchte Jørgensen \& Domenico De Giovanni: Time Charters with Purchase Options in Shipping: Valuation and Risk Management.

F-2008-04 Stig V. Møller: Habit persistence: Explaining cross-sectional variation in returns and time-varying expected returns.

F-2008-03 Thomas Poulsen: Private benefits in corporate control transactions.

F-2008-02 Thomas Poulsen: Investment decisions with benefits of control.

F-2008-01 Thomas Kokholm: Pricing of Traffic Light Options and other Correlation Derivatives.

F-2007-03 Domenico De Giovanni: Lapse Rate Modeling: A Rational Expectation Approach.

F-2007-02 Andrea Consiglio \& Domenico De Giovanni: Pricing the Option to Surrender in Incomplete Markets.

F-2006-09 Peter Løchte Jørgensen: Lognormal Approximation of Complex Pathdependent Pension Scheme Payoffs.

F-2006-08 Peter Løchte Jørgensen: Traffic Light Options.

F-2006-07 David C. Porter, Carsten Tanggaard, Daniel G. Weaver \& Wei Yu: Dispersed Trading and the Prevention of Market Failure: The Case of the Copenhagen Stock Exhange.

F-2006-06 Amber Anand, Carsten Tanggaard \& Daniel G. Weaver: Paying for Market Quality.

F-2006-05 Anne-Sofie Reng Rasmussen: How well do financial and macroeconomic variables predict stock returns: Time-series and cross-sectional evidence.

F-2006-04 Anne-Sofie Reng Rasmussen: Improving the asset pricing ability of the Consumption-Capital Asset Pricing Model.

F-2006-03 Jan Bartholdy, Dennis Olson \& Paula Peare: Conducting event studies on a small stock exchange.

F-2006-02 Jan Bartholdy \& Cesário Mateus: Debt and Taxes: Evidence from bankfinanced unlisted firms.

F-2006-01 Esben P. Høg \& Per H. Frederiksen: The Fractional Ornstein-Uhlenbeck Process: Term Structure Theory and Application. 
F-2005-05 Charlotte Christiansen \& Angelo Ranaldo: Realized bond-stock correlation: macroeconomic announcement effects.

F-2005-04 Søren Willemann: GSE funding advantages and mortgagor benefits: Answers from asset pricing.

F-2005-03 Charlotte Christiansen: Level-ARCH short rate models with regime switching: Bivariate modeling of US and European short rates.

F-2005-02 Charlotte Christiansen, Juanna Schröter Joensen and Jesper Rangvid: Do more economists hold stocks?

F-2005-01 Michael Christensen: Danish mutual fund performance - selectivity, market timing and persistence.

F-2004-01 Charlotte Christiansen: Decomposing European bond and equity volatility. 
ISBN 9788778823670

Department of Business Studies

Aarhus School of Business

University of Aarhus

Fuglesangs Allé 4

DK-8210 Aarhus V - Denmark

Tel. +4589486688

Fax +4586150188

www.asb.dk 